\title{
New bifunctional chelators incorporating dibromomaleimide groups for radiolabeling of antibodies with PET imaging radioisotopes
}

\section{Supporting Information}

\begin{abstract}
Matthew Farleigh, ${ }^{1}$ Truc Thuy Pham, ${ }^{1}$ Zilin Yu, ${ }^{1}$ Jana Kim, ${ }^{1}$ Kavitha Sunassee,,${ }^{1}$ George Firth, ${ }^{1}$ Nafsika Forte, ${ }^{2}$ Vijay Chudasama, ${ }^{2}$ James R. Baker, ${ }^{2}$ Nicholas J. Long, ${ }^{3}$ Charlotte Rivas ${ }^{* 1}$, Michelle T. Ma*1

${ }^{1}$ School of Biomedical Engineering and Imaging Sciences, King's College London, St Thomas' Hospital, London, SE1 7EH, UK

${ }^{2}$ Department of Chemistry, University College London, 20 Gordon Street, London, WC1H OAJ, UK

${ }^{3}$ Department of Chemistry, Imperial College London, Molecular Sciences Research Hub, London, W12 OBZ, UK

*charlotte.rivas@kcl.ac.uk, michelle.ma@kcl.ac.uk
\end{abstract}

\section{Table of Contents}

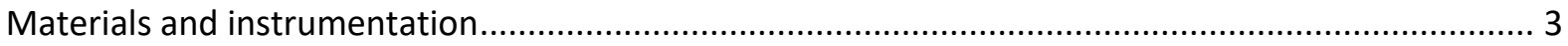

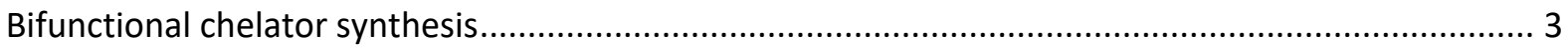

Preparation of sar-dtm-trastuzumab and dfo-dtm-trastuzumab immunoconjugates .......................... 4

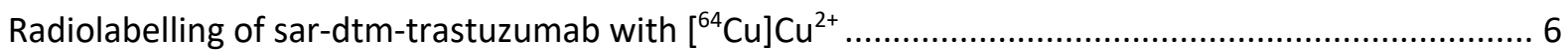

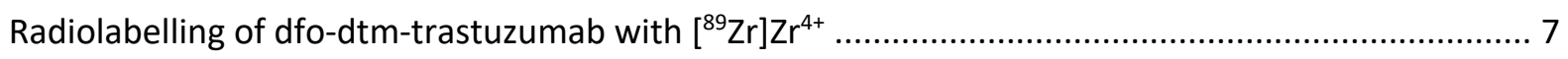

Serum stability and target receptor affinity of $\left[{ }^{64} \mathrm{Cu}\right] \mathrm{Cu}$-sar-dtm-trastuzumab and $\left[{ }^{89} \mathrm{Zr}\right] \mathrm{Zr}$-dfo-dtm-

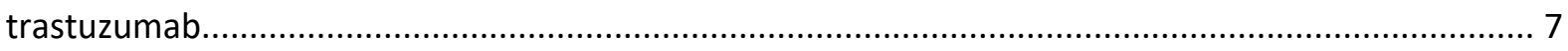

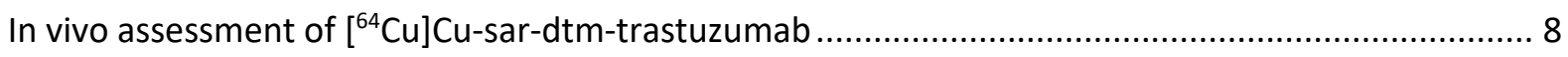

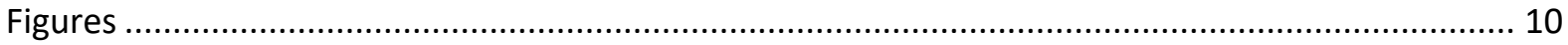

Figure S1. SDS-PAGE of conjugation reaction between reduced trastuzumab and sar-dbm .......... 10

Figure S2. SDS-PAGE of conjugation reaction between reduced trastuzumab and dfo-dbm.......... 11

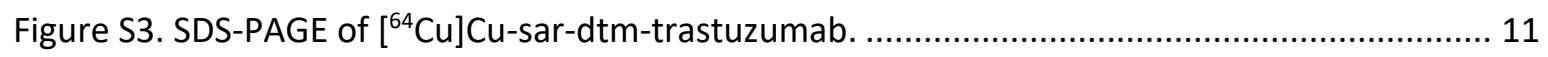

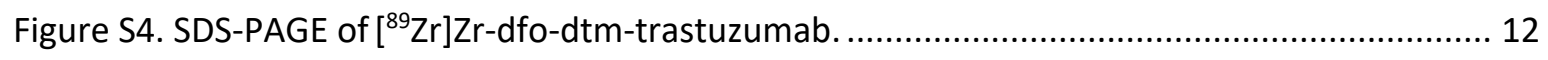

Figure S5. SDS-PAGE of sar-dtm-trastuzumab and dfo-dtm-trastuzumab ..................................... 12

Figure S6. High resolution ESI deconvoluted mass spectrum of sar-dtm-trastuzumab................... 13

Figure S7. High resolution ESI deconvoluted mass spectrum of dfo-dtm-trastuzumab ................... 14 
Figure S8. Size exclusion HPLC chromatograms of $\left[{ }^{64} \mathrm{Cu}\right] \mathrm{Cu}$-sar-dtm-trastuzumab incubated with serum

Figure S9. Size exclusion HPLC chromatograms of $\left[{ }^{89} \mathrm{Zr}\right] \mathrm{Zr}$-dfo-dtm-trastuzumab incubated with serum

Figure S10. Cell binding study of $\left[{ }^{64} \mathrm{Cu}\right] \mathrm{Cu}$-sar-dtm-trastuzumab with HER2-positive SKOV3 cells. 15 Figure S11. Biodistribution of $\left[{ }^{64} \mathrm{Cu}\right] \mathrm{Cu}$-sar-dtm-trastuzumab in healthy female NOD scid gamma mice determined from PET/CT imaging. 16

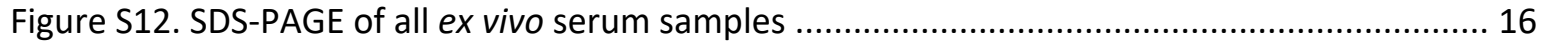

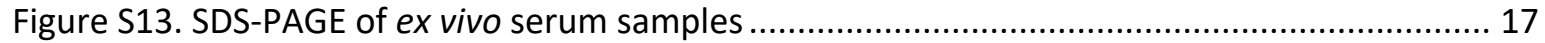

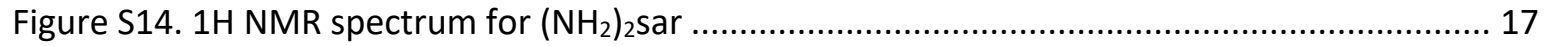

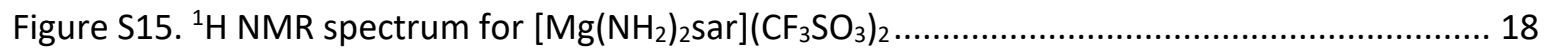

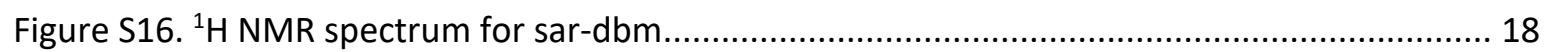

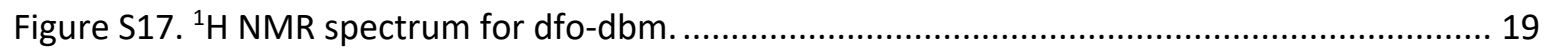

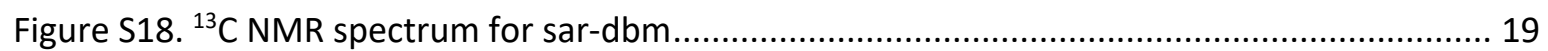

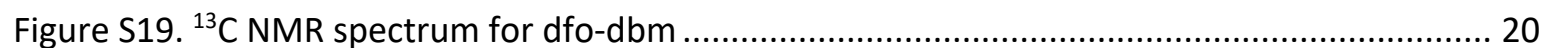

Figure S20. High-resolution ESI-mass spectrum for sar-dbm ..................................................... 21

Figure S21. High-resolution ESI-mass spectrum for dfo-dbm .................................................... 22

Figure S22. Analytical C18 reverse-phase HPLC chromatograms of sar-dbm and dfo-dbm ............ 23

Figure S23. LC-MS analysis of a crude reaction mixture containing sar-dbm and sar-dbm $\mathrm{db}_{2} \ldots \ldots \ldots . . .23$

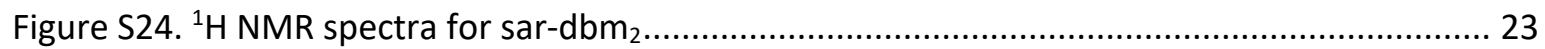

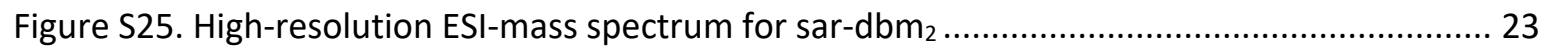

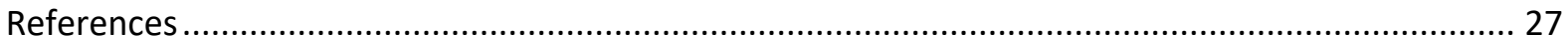




\section{Materials and instrumentation}

Chemicals and reagents were obtained from Sigma-Aldrich (Dorset, UK) unless otherwise specified. The highest available purity (lowest metal ion-containing) chemicals were used. $18.2 \mathrm{M} \Omega$ water was used to prepare all solutions. PD-10 size exclusion columns were purchased from GE Healthcare UK Ltd. (Buckinghamshire, UK). Trastuzumab was obtained as the biosimilar Herzuma in solution $(21 \mathrm{mg} / \mathrm{mL}$ ) from the Pharmacy Department at Guy's and St. Thomas' NHS Trust, London. Fresh human serum was obtained from a healthy volunteer. Preparative high-performance liquid chromatography (HPLC) purification was carried out using an Agilent PrepStar LC system with in-line UV. NMR spectra were acquired on either a Bruker $400 \mathrm{MHz}$ spectrometer, or a Bruker $700 \mathrm{MHz}$ (Bruker UK Limited, Coventry, UK). NMR spectra were referenced to residual solvent signals, or in the case where deuterium oxide was the solvent in ${ }^{13} \mathrm{C}$ NMR spectra, a trifluoroacetic acid reference was used. Analytical reverse phase HPLC was carried out using an Agilent 1260 Infinity II equipped with an Eclipse XDB-C18 column $(4.6 \times 150 \mathrm{~mm}, 5 \mu \mathrm{m})$ with a $1 \mathrm{~mL} \mathrm{~min}^{-1}$ flow rate and UV spectroscopic detection at $220 \mathrm{~nm}, 254 \mathrm{~nm}$, and $330 \mathrm{~nm}$, and a gradient mobile phase with a flow rate of $1 \mathrm{~mL} \mathrm{~min}^{-1}$. (Gradient: $\mathrm{A}=0.1 \% \mathrm{FA}$ in water, $\mathrm{B}=$ $0.1 \% \mathrm{FA}$ in acetonitrile. $0-2 \mathrm{~min} 5 \% \mathrm{~B}$ in $\mathrm{A}, 2-11 \mathrm{~min} 5 \% \rightarrow 95 \% \mathrm{~B}$ in $\mathrm{A}, 12-12.10 \mathrm{~min} 95 \% \rightarrow 5 \% \mathrm{~B}$ in $\mathrm{A}, 12.10-15$ $\min 5 \%$ in A.) Instant thin layer chromatography strips (ITLC-SG) were obtained from Varian Medical Systems UK, Ltd. (Crawley, UK), and ITLC strips were visualised using a Lab Logic B-MS-1000 plate reader with a B-FC$2000 \mathrm{P}$ detector equipped with a B-FC-3600 photomultiplier. Analytical size exclusion radioHPLC traces were acquired using an Agilent 1200 Series HPLC system with an in-line radioactivity detector (Ray Test Gabi with a Ray Test Na-I 1x1" Std. detector). A BioSep ${ }^{\mathrm{TM}}$ SEC-s2000 LC Column $(5 \mu \mathrm{m}, 145 \AA$ A $300 \times 7.8 \mathrm{~mm})$ was used with a mobile phase of PBS and sodium ethylenediamine tetraacetate $(2 \mathrm{mM})$ at a flow rate of $1 \mathrm{~mL} \mathrm{~min}^{-1}$.

\section{Bifunctional chelator synthesis}

$\left[\mathrm{Mg}\left(\mathrm{NH}_{2}\right)_{2} \mathrm{Sar}\right]\left(\mathrm{CF}_{3} \mathrm{SO}_{3}\right)_{2}$

$\left(\mathrm{NH}_{2}\right)_{2}$ sar was synthesised following literature methods. ${ }^{1,2}$ Preparation of $\left[\mathrm{Mg}\left(\mathrm{NH}_{2}\right)_{2} \mathrm{Sar}\right]\left(\mathrm{CF}_{3} \mathrm{SO}_{3}\right)_{2}$ was adapted from the literature. ${ }^{3}\left(\mathrm{NH}_{2}\right)_{2} \mathrm{sar}(100 \mathrm{mg}, 318 \mu \mathrm{mol})$ and $\mathrm{Mg}\left(\mathrm{CF}_{3} \mathrm{SO}_{3}\right)_{2}(103 \mathrm{mg}, 318 \mu \mathrm{mol})$ were dissolved in dry acetonitrile $(5 \mathrm{~mL})$ and refluxed for $30 \mathrm{~min}$, then cooled to room temperature. The solution was then evaporated to dryness to yield a white solid. $\left[\mathrm{Mg}\left(\mathrm{NH}_{2}\right)_{2} \mathrm{sar}\right]\left(\mathrm{CF}_{3} \mathrm{SO}_{3}\right)_{2}: 176 \mathrm{mg}, 277 \mu \mathrm{mol}, 87 \% .{ }^{1} \mathrm{H} \mathrm{NMR}\left(400 \mathrm{MHz}, \mathrm{D}_{2} \mathrm{O}\right) \delta$ $3.61(\mathrm{~m}, 6 \mathrm{H}), 3.15(\mathrm{~m}, 12 \mathrm{H}), 2.68(\mathrm{~m}, 6 \mathrm{H}), 2.42(\mathrm{~m}, 6 \mathrm{H})$.

sar-dbm

$\left[\mathrm{Mg}\left(\mathrm{NH}_{2}\right)_{2} \mathrm{sar}\right]\left(\mathrm{CF}_{3} \mathrm{SO}_{3}\right)_{2}(250 \mathrm{mg}, 393 \mu \mathrm{mol}, 1$ eq.) was dried in vacuo; separately 3,4-dibromo-maleimide- $\mathrm{N}$ hexanoic acid ${ }^{4}(446 \mathrm{mg}, 1.214 \mathrm{mmol}, 3$ eq.) and EEDQ $(296 \mathrm{mg}, 1.197 \mathrm{mmol}, 3 \mathrm{eq}$ ) were also dried in vacuo. 3,4dibromo-maleimide- $\mathrm{N}$-hexanoic acid and EEDQ were added to dry acetonitrile $(20 \mathrm{~mL})$ and stirred for 1 hour at ambient temperature. $\left[\mathrm{Mg}\left(\mathrm{NH}_{2}\right)_{2} \mathrm{sar}\right]\left(\mathrm{CF}_{3} \mathrm{SO}_{3}\right)_{2}$ was added and the reaction was stirred for 3 hours at ambient temperature. Glacial acetic acid $(12.5 \mathrm{~mL})$ was then added and the solution evaporated to dryness. Water (10 $\mathrm{mL}$ ) was added to the dry residue, and the supernatant was separated from insoluble material. The supernatant was lyophilised to give a white powder, containing the desired product. The crude product was purified by preparative reverse phase HPLC (Agilent PrepHT XDB-C18) using mobile phase A (water with $0.1 \%$ trifluoroacetic acid) and mobile phase $B$ (acetonitrile with $0.1 \%$ trifluoroacetic acid) with an eluting gradient $\left(10 \mathrm{~mL} \mathrm{~min}{ }^{-1}, 0-5\right.$ $\min 0 \% \mathrm{~B}$ in $\mathrm{A}, 5-10 \mathrm{~min} 0 \% \rightarrow 20 \% \mathrm{~B}$ in A, 10-40 $\min 20 \% \rightarrow 60 \% \mathrm{~B}$ in A). The product was eluted in a single fraction (retention time $21.5 \mathrm{~min}$ ) which was lyophilised to give an off-white powder (20.7 $\mathrm{mg}, 8 \%$ yield). ${ }^{1} \mathrm{H}$ $\operatorname{NMR}\left(700 \mathrm{MHz}, \mathrm{D}_{2} \mathrm{O}\right) \delta 3.50(\mathrm{~s}, 3 \mathrm{H}), 3.45(\mathrm{t}, J=8.2 \mathrm{~Hz}, 2 \mathrm{H}), 3.15(\mathrm{~s}, 12 \mathrm{H}), 3.00(\mathrm{~s}, 12 \mathrm{H}), 2.28(\mathrm{~s}, 3 \mathrm{H}), 2.11(\mathrm{t}, J=$ $8.2 \mathrm{~Hz}, 2 \mathrm{H}), 1.43(\mathrm{~m}, 4 \mathrm{H}), 1.12(\mathrm{~m}, 2 \mathrm{H}) .{ }^{13} \mathrm{C}$ NMR $\left(176 \mathrm{MHz}, \mathrm{D}_{2} \mathrm{O}\right) \delta 178.55,166.45,129.33,55.91,54.92,50.83$, $50.45,47.86,46.14,39.47,35.94,27.44,25.55,24.34$. High resolution ESI-MS +ve mode, $\left[\mathrm{C}_{24} \mathrm{H}_{44} \mathrm{Br}_{2} \mathrm{~N}_{9} \mathrm{O}_{3}\right]^{+} \mathrm{m} / \mathrm{z}=$ 666.1915 (observed), 666.1936 (expected). Analytical HPLC retention time, $5.92 \mathrm{~min}$ (see materials and instrumentation for HPLC specifications). See Figures S16, S18, S20 and S22. 
$d f o-d b m$

3,4-Dibromo-maleimide-1-acetic acid ${ }^{4}(100 \mathrm{mg}, 321 \mu \mathrm{mol}$ ) and EEDQ (279 mg, $1.13 \mathrm{mmol}$ ) were dissolved in dimethylsulfoxide (DMSO) (4 mL) with stirring. Desferrioxamine (dfo) mesylate (627 mg, $963 \mu \mathrm{mol}$ ) was added, and the reaction was stirred for $3 \mathrm{~h}$. The reaction was then quenched by the addition of TFA (40 $\mu \mathrm{L})$. The crude product was purified by preparative reverse phase HPLC (Agilent PrepHT XDB-C18) using mobile phase A (water with $0.1 \%$ trifluoroacetic acid) and mobile phase $B$ (acetonitrile with $0.1 \%$ trifluoroacetic acid) with an eluting gradient (10 mL min ${ }^{-1}, 0-10$ min $5 \%$ B in A, 10-60 min $5 \% \rightarrow 35 \%$ B in A). The product was obtained in one fraction which was lyophilised to give a white powder, $61.2 \mathrm{mg}$ (retention time $43.5 \mathrm{~min}, 22 \%$ yield). ${ }^{1} \mathrm{H}$ NMR (400 MHz, DMSO) $\delta 9.57(\mathrm{~s}, 3 \mathrm{H}), 8.13(\mathrm{t}, J=5.5 \mathrm{~Hz}, 1 \mathrm{H}), 7.74(\mathrm{t}, J=5.2 \mathrm{~Hz}, 2 \mathrm{H}), 4.08(\mathrm{~s}, 2 \mathrm{H}), 3.45(\mathrm{t}, J=7.0 \mathrm{~Hz}$, $6 \mathrm{H}), 3.07-2.96(\mathrm{~m}, 6 \mathrm{H}), 2.57(\mathrm{t}, J=7.1 \mathrm{~Hz}, 4 \mathrm{H}), 2.27(\mathrm{t}, J=7.3 \mathrm{~Hz}, 4 \mathrm{H}), 1.96(\mathrm{~s}, 3 \mathrm{H}), 1.55-1.45(\mathrm{~m}, 6 \mathrm{H}), 1.43-$ $1.32(\mathrm{~m}, 6 \mathrm{H}), 1.28-1.16(\mathrm{~m}, 6 \mathrm{H}) .{ }^{13} \mathrm{C}$ NMR $(101 \mathrm{MHz}$, DMSO) $\delta 171.95,171.25,170.12,165.26,163.91,129.50$, 47.07, 41.41, 39.52, 38.38, 29.90, 28.77, 27.52, 25.99, 23.46, 20.28. High-resolution ESI-MS +ve mode, $\left[\mathrm{C}_{31} \mathrm{H}_{50} \mathrm{Br}_{2} \mathrm{~N}_{7} \mathrm{O}_{11}\right]^{+} \mathrm{m} / \mathrm{z}=856.1912$ (observed), $\mathrm{m} / \mathrm{z}=856.1915$ (expected). Analytical HPLC retention time, 7.95 min (see materials and instrumentation for HPLC specifications). See Figures S17, S19, S21 and S22.

\section{Preparation of sar-dtm-trastuzumab and dfo-dtm-trastuzumab immunoconjugates}

\section{sar-dtm-trastuzumab}

This method was modified from the literature. ${ }^{5}$ Trastuzumab $(5 \mathrm{mg})$ was dissolved in aqueous borate buffered saline (BBS, $1.5 \mathrm{~mL}$ ) solution ( $50 \mathrm{mM}$ sodium borate, $50 \mathrm{mM} \mathrm{NaCl}$, and $5 \mathrm{mM}$ ethylenediaminetetraacetic acid (EDTA), $\mathrm{pH} 8.5$ ) to give an antibody concentration of $23 \mu \mathrm{M}$. To this antibody solution was added tris(2carboxyethyl)phosphine solution (TCEP, $10 \mathrm{mM}$ in BBS, $21 \mu \mathrm{L}, 6$ eq.) and warmed at $37^{\circ} \mathrm{C}$ for $2 \mathrm{~h}$. Then sar-dbm (10 $\mathrm{mM}$ in water, $28 \mu \mathrm{L}, 8$ eq.) was added to the reduced antibody solution where a colour change from a colourless to pale yellow solution was observed. This solution was then warmed at $37{ }^{\circ} \mathrm{C}$ for $48 \mathrm{~h}$. The bioconjugate was loaded onto a PD-10 column (preconditioned with aqueous ammonium acetate (0.2 M) solution) and eluted with aqueous ammonium acetate $(0.2 \mathrm{M})$ in $0.5 \mathrm{~mL}$ fractions. Fraction protein content was assessed using a NanoDrop ${ }^{\mathrm{TM}} 2000$ spectrophotometer. Fractions 6 and 7 were combined, and further purified and buffer exchanged into aqueous ammonium acetate $(0.1 \mathrm{M})$ by six cycles of spin filtration (4000 rcf, $15 \mathrm{~min}$ ) through a Vivaspin (50 kDa MWCO). The bioconjugate sar-dtm-trastuzumab (3.62 mg) was recovered in $200 \mu \mathrm{L}$ solution at a concentration of $125 \mu \mathrm{M}$.

\section{dfo-dtm-trastuzumab}

This method is modified from the literature. ${ }^{5}$ Trastuzumab $(5 \mathrm{mg}$ ) was dissolved in borate buffered saline (BBS, $1.5 \mathrm{~mL}$ ) solution ( $50 \mathrm{mM}$ sodium borate, $50 \mathrm{mM} \mathrm{NaCl}$, and $5 \mathrm{mM}$ ethylenediaminetetraacetic acid (EDTA), $\mathrm{pH}$ 8.5) to give an antibody concentration of $23 \mu \mathrm{M}$. To this antibody solution was added tris(2carboxyethyl)phosphine solution (TCEP, $10 \mathrm{mM}$ in BBS, $21 \mu \mathrm{L}, 6$ eq.) and warmed at $37^{\circ} \mathrm{C}$ for $2 \mathrm{~h}$. Then DFO-dbm (10 mM in DMF, $28 \mu \mathrm{L}, 8$ eq.) was added to the reduced antibody solution where a colour change from a colourless to pale yellow solution was observed. This solution was then left for two hours at room temperature. The bioconjugate was loaded onto a PD-10 column (preconditioned with aqueous ammonium acetate (0.2 M) solution) and eluted with ammonium acetate $(0.2 \mathrm{M})$ in $0.5 \mathrm{~mL}$ fractions. Fraction protein content was assessed using a NanoDrop ${ }^{\mathrm{TM}} 2000$ spectrophotometer. Fractions 6 and 7 were combined, and further purified and buffer exchanged into aqueous ammonium acetate $(0.1 \mathrm{M}$ ) by six cycles of spin filtration (4000 rcf, $15 \mathrm{~min}$ ) through a Vivaspin ( $50 \mathrm{kDa}$ MWCO). The bioconjugate dfo-dtm-trastuzumab $(2.36 \mathrm{mg}$ ) was recovered in $200 \mu \mathrm{L}$ solution at a concentration of $81 \mu \mathrm{M}$. 


\section{SDS-PAGE analysis of trastuzumab conjugates}

These methods are adapted from the literature. ${ }^{5} \mathrm{~A}$ sample of immunoconjugate $(3 \mu \mathrm{L})$ was diluted with water $(10 \mu \mathrm{L})$, followed by addition of SDS-PAGE loading buffer $(2 \mu \mathrm{L})$. This solution was mixed thoroughly and then heated to $65^{\circ} \mathrm{C}$ for $5 \mathrm{~min}$ to denature the protein. The sample was then loaded onto the gel $(12 \%$ acrylamide with $4 \%$ stacking gel), along with a molecular weight marker, a sample of trastuzumab (prepared in the same way), and a sample of reduced trastuzumab (also prepared in the same way). The stability of the bioconjugates in the presence of a large excess of thiol was also assessed by preparing samples in the same fashion as described above, with the addition inclusion of dithiothreitol (DTT) (10 mM in water, $1 \mu \mathrm{L}, \geq 100$ eq.) prior to denaturing. Separation of protein components was achieved by applying a constant voltage to the gels ( $35 \mathrm{~mA}, 35 \mathrm{~min}$ ) in SDS running buffer. Gels were stained with Coomassie blue, destained, and then bright light imaged (Invitrogen, iBright FL1000, Thermo Fisher Scientific).

\section{ESI-MS analysis of bioconjugates}

Molecular masses were measured using an Agilent 6510 QTOF LC-MS system (Agilent, UK). An Agilent 1200 HPLC system was equipped with an Agilent PLRP-S, 1000A, $8 \mu \mathrm{M}, 150 \mathrm{~mm} \times 2.1 \mathrm{~mm}$ column. Bioconjugates were buffer exchanged to ammonium acetate $(0.2 \mathrm{M}, \mathrm{pH}$ 6.9) using a Vivaspin (50 kDa MWCO) to a final concentration of $6.5 \mu \mathrm{M}$. To $100 \mu \mathrm{L}$ of this bioconjugate solution was added PNGase $\mathrm{F}\left(1.0 \mu \mathrm{L}\right.$, New England Biolabs) at $37^{\circ} \mathrm{C}$ for $16 \mathrm{~h}$. After this time, the sample was diluted to $1.8 \mu \mathrm{M}$ with ammonium acetate buffer (0.2 M, pH 6.9). $10 \mu \mathrm{L}$ of bioconjugate sample $(1.8 \mu \mathrm{M})$ was injected on the column using mobile phase $A$ (water- $0.1 \%$ formic acid) and $B$ (acetonitrile- $0.1 \%$ formic acid) with an eluting gradient (as shown in Table S1) at a flow rate of $300 \mu \mathrm{l} / \mathrm{min}$. The oven temperature was maintained at $60^{\circ} \mathrm{C}$. An Agilent 6510 QTOF mass spectrometer was operated in a positive polarity mode, coupled with an ESI ion source. The ion source parameters were set up with a VCap of $3500 \mathrm{~V}$, a gas temperature at $350^{\circ} \mathrm{C}$, a dry gas flow rate at $10 \mathrm{~L} / \mathrm{min}$ and a nebulizer of $30 \mathrm{psig}$. MS ToF was acquired under conditions of a fragmentor at $350 \mathrm{~V}$, a skimmer at $65 \mathrm{~V}$ and an acquisition rate at $0.5 \mathrm{spectra} / \mathrm{s}$ in a profile mode, within a scan range between 700 and $5000 \mathrm{~m} / \mathrm{z}$. The data was then analysed by deconvoluting to a zero charge mass spectrum using a maximum entropy deconvolution algorithm.

Table S1. LC-MS mobile phase A/ B gradient elution.

\begin{tabular}{ccc}
\hline Time $(\min )$ & Solvent $\mathbf{A}(\%)$ & Solvent B (\%) \\
\hline 0.0 & 85 & 15 \\
1.0 & 85 & 15 \\
1.50 & 68 & 32 \\
2.0 & 68 & 32 \\
7.0 & 50 & 50 \\
9.0 & 5 & 95 \\
10.0 & 5 & 95 \\
12.0 & 85 & 15 \\
15.0 & 85 & 15
\end{tabular}


Table S2: ESI-MS data for trastuzumab and chelator-trastuzumab conjugates

\begin{tabular}{ccc}
\hline Antibody species & $\mathbf{m} / \mathbf{z}$ (observed) & $\mathbf{m} / \mathbf{z}$ (calculated) \\
\hline trastuzumab & & \\
HHLL & 145186 & \\
\hline sar-dtm-trastuzumab & & \\
L + 1 sar & 23970 & 23963 \\
$H L+1$ sar & 73126 & 73116 \\
$H L+2$ sar & 73646 & 73639 \\
$H H L L+1$ sar & 145694 (weak) & 145709 \\
$H H L L+2$ sar & 146236 & 146232 \\
HHLL + 3 sar & 146746 & 146755 \\
HHLL + 4 sar & 147277 & 147278 \\
\hline DFO-dtm-trastuzumab & & \\
$H L+1$ DFO & 73307 & 73305 \\
$H L+2$ DFO & 74015 & 74017 \\
$H H L L+2$ DFO & 146604 & 146610 \\
$H H L L+3$ DFO & 147324 & 147322 \\
$H H L L+4$ DFO & 148032 & 148034 \\
\hline
\end{tabular}

\section{Radiolabelling of sar-dtm-trastuzumab with $\left[{ }^{64} \mathrm{Cu}\right] \mathrm{Cu}^{2+}$}

\section{$\left[{ }^{64} \mathrm{Cu}\right] \mathrm{Cu}^{2+}$ production and purification}

A concave high purity gold target was electroplated with [ $\left.{ }^{64} \mathrm{Ni}\right] \mathrm{Ni}$ ( $95.6 \%$ isotopically enriched), rinsed with water and then dried. ${ }^{6}$ This target was then irradiated with protons on a CTI RDS 112 cyclotron (11 MeV, $1 \mathrm{~cm}$ beam diameter) with a beam current of $30 \mu \mathrm{A}$, for $8 \mathrm{~h}$ to induce the ${ }^{64} \mathrm{Ni}(\mathrm{p}, \mathrm{n}){ }^{64} \mathrm{Cu}$ reaction. $\mathrm{HCl}(9 \mathrm{M}, 150 \mu \mathrm{L})$ was added to the irradiated surface and then evaporated at $95{ }^{\circ} \mathrm{C}$. This was repeated three times. $\mathrm{HCl}(9 \mathrm{M}, 300 \mu \mathrm{L})$ was added to the irradiated surface and then transferred to an anion exchange column ( $\mathrm{AG}^{\circledR}{ }^{\circledR} 1-\mathrm{X} 8$ Anion Exchange Resin, pre-rinsed with water and $\mathrm{HCl}(6 \mathrm{M}))$. This step was repeated three times to give a total of $900 \mu \mathrm{L}$ added to the column. The column was then eluted sequentially under gravity with $6 \mathrm{M} \mathrm{HCl}(5 \mathrm{~mL})$ to remove excess $\left[{ }^{64} \mathrm{Ni}^{2} \mathrm{Ni}^{2+}\right.$; followed by $4 \mathrm{M} \mathrm{HCl}(5 \mathrm{~mL})$, to remove any radio-cobalt impurities; $0.1 \mathrm{M} \mathrm{HCl}(10 \mathrm{~mL})$ was used to elute $\left[{ }^{64} \mathrm{Cu}\right] \mathrm{Cu}^{2+}$. Twenty fractions ( $1 \mathrm{~mL}$ each) were collected in total. Fractions 14 and 15 contained the majority of the $\left[{ }^{64} \mathrm{Cu}\right] \mathrm{Cu}^{2+}$ produced, with a radionuclidic purity greater than $99.9 \%$.

Radiolabelling of sar-dtm-trastuzumab with $\left[{ }^{64} \mathrm{Cu}\right] \mathrm{Cu}^{2+}$

An aliquot from fraction 15 containing $\left[{ }^{64} \mathrm{Cu}\right] \mathrm{Cu}^{2+}(56.5 \mathrm{MBq}, 448 \mu \mathrm{L})$ was dried under a stream of $\mathrm{N}_{2}$ at $100{ }^{\circ} \mathrm{C}$, and then redissolved in aqueous ammonium acetate solution $(0.1 \mathrm{M}, 339 \mu \mathrm{L})$. A sample of $\left[{ }^{64} \mathrm{Cu}\right] \mathrm{Cu}^{2+}$ from this solution ( $5 \mathrm{MBq}, 30 \mu \mathrm{L}$ ) was then added to an aqueous solution of sar-dtm-trastuzumab (100 $\mu \mathrm{g}$, in $9.4 \mu \mathrm{L}$ of 0.1 $\mathrm{M}$ ammonium acetate). The sample was agitated, and left at ambient temperature for 5 min. Radiochemical yields were determined using ITLC-SG strips spotted with $1 \mu \mathrm{L}$ of radiolabelling mixture, which were developed in a mobile phase of $0.1 \mathrm{M}$ citrate buffer ( $\mathrm{pH} 5.5)$. For $\left[{ }^{64} \mathrm{Cu}\right] \mathrm{Cu}$-sar-dtm-trastuzumab: $R_{\mathrm{f}}<0.1$; for unreacted $\left[{ }^{64} \mathrm{Cu}\right] \mathrm{Cu}^{2+}: R_{\mathrm{f}}>0.9$. Size exclusion HPLC (see materials and instrumentation) was also used to assess radiochemical yield. $\left[{ }^{64} \mathrm{Cu}\right] \mathrm{Cu}$-sar-dtm-trastuzumab had a retention time of $7.75 \mathrm{~min}$, and unreacted $\left[{ }^{64} \mathrm{Cu}\right] \mathrm{Cu}{ }^{2+}$ eluted at $11.58 \mathrm{~min}$. Near quantitative radiochemical yields (> 98\%) were achieved at a specific activity of 43.6

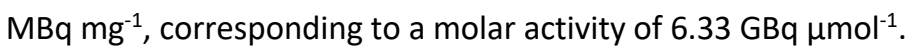

$\left.{ }^{[64} \mathrm{Cu}\right] \mathrm{Cu}^{2+}$ radiolabelling of sar-dtm-trastuzumab at varying concentrations of bioconjugate

An aliquot from fraction 15 containing $\left[{ }^{64} \mathrm{Cu}\right] \mathrm{Cu}^{2+}(1 \mathrm{MBq})$ was dried under a stream of $\mathrm{N}_{2}$ at $100{ }^{\circ} \mathrm{C}$, and then redissolved in aqueous ammonium acetate solution $(0.1 \mathrm{M}, 20 \mu \mathrm{L})$ to give a $50 \mathrm{kBq} \mathrm{LL}^{-1}$ solution (pH 7). Sar-dtmtrastuzumab was diluted to $125 \mu \mathrm{M}$ in ammonium acetate $(0.1 \mathrm{M})$. To $8 \mu \mathrm{L}$ of this bioconjugate solution was added $2 \mu \mathrm{L}(100 \mathrm{kBq})$ of $\left[{ }^{64} \mathrm{Cu}\right] \mathrm{Cu}^{2+}$ in ammonium acetate $(0.1 \mathrm{M})$, agitated and then left at room temperature 
for $5 \mathrm{~min}$ (this dilution gives a $100 \mu \mathrm{M}$ solution). ITLC was used to assess radiochemical yield. This process was repeated at bioconjugate concentrations of $10 \mu \mathrm{M}, 1 \mu \mathrm{M}, 100 \mathrm{nM}, 10 \mathrm{nM}$, and $1 \mathrm{nM}$.

Radiolabelling of sar-dtm-trastuzumab with $\left[{ }^{64} \mathrm{Cu}\right] \mathrm{Cu}^{2+}$ for in vivo assessment

Aliquots from fraction $14(132 \mu \mathrm{L}, 28 \mathrm{MBq})$ and fraction $15(1 \mathrm{~mL}, 73.4 \mathrm{MBq})$ were combined and dried under a stream of $\mathrm{N}_{2}$ at $100^{\circ} \mathrm{C}$, and then redissolved in aqueous ammonium acetate solution $(0.1 \mathrm{M}, 573 \mu \mathrm{L})$. A sample of $\left[{ }^{64} \mathrm{Cu}\right] \mathrm{Cu}^{2+}$ from this solution $(225 \mu \mathrm{L}, 32.7 \mathrm{MBq}$ ) was then added to sar-dtm-trastuzumab (3.21 mg, $330 \mu \mathrm{L}$, in $0.1 \mathrm{M}$ ammonium acetate). The sample was agitated, and left at ambient temperature for $5 \mathrm{~min}$. As above, ITLC and size exclusion HPLC were used to assess radiochemical yield. Near quantitative radiochemical yields $(>99 \%)$ were obtained at a specific activity of $10.19 \mathrm{MBq} \mathrm{mg}^{-1}$ corresponding to a molar activity of $1.48 \mathrm{GBq}_{\mu \mathrm{mol}}{ }^{-1}$.

\title{
Radiolabelling of dfo-dtm-trastuzumab with [ ${ }^{89} \mathrm{Zr}_{\mathrm{Zr}}{ }^{4+}$
}

\author{
Preparation of $\left.{ }^{89} \mathrm{Zr}\right] Z r^{4+}$ in HEPES buffer
}

No-carrier-added $\left.{ }^{89} \mathrm{Zr}_{\mathrm{Z}}\right] \mathrm{rr}^{4+}$ (radionuclidic purity $>99.9 \%$ ) produced at the BV Cyclotron, Amsterdam, was purchased from Perkin Elmer, and was received as $\left.{ }^{89} \mathrm{Zr}\right]\left[\mathrm{Zr}(\mathrm{ox})_{4}\right]$ (ox = oxalate). Oxalate was removed from solution using reported methods. ${ }^{7}$ Briefly, SEP-Pak light QMA cartridge was preconditioned with EtOH $(5 \mathrm{~mL})$, saline $(0.9 \%, 10 \mathrm{~mL})$, and water $\left.(10 \mathrm{~mL}) .{ }^{89} \mathrm{Zr}\right]\left[\mathrm{Zr}(\mathrm{ox})_{4}\right]$ (ox = oxalate) was diluted with water to a total volume of $250 \mu \mathrm{L}$ and then loaded onto the preconditioned purification cartridge. The cartridge was washed with water $(10 \mathrm{~mL})$ to remove oxalic acid. To elute ${ }^{89} \mathrm{Zr}_{\mathrm{Z}} \mathrm{Zr}^{4+}$, a solution of aqueous $\mathrm{HCl}(0.5 \mathrm{~mL}, 1 \mathrm{M})$ was used: the first 150 $\mu \mathrm{L}$ was discarded, and the remaining $350 \mu \mathrm{L}$ contained $\left[{ }^{89} \mathrm{Zr}\right] \mathrm{Zr}^{4+}$, which was then dried under a stream of $\mathrm{N}_{2}$ at $100^{\circ} \mathrm{C}$. This was then re-dissolved in aqueous HEPES buffer $(0.2 \mathrm{M}, \mathrm{pH} 7)$.

Radiolabelling of dfo-dtm-trastuzumab with ${ }^{89} \mathrm{Zr}_{\mathrm{Z}} \mathrm{Zr}^{4+}$

The dfo-dtm-trastuzumab bioconjugate was diluted to a concentration of $50 \mu \mathrm{M}$ in ammonium acetate (0.1 M). To $10 \mu \mathrm{L}$ of this solution was added $5 \mu \mathrm{L}$ of $\left[{ }^{89} \mathrm{Zr}_{\mathrm{ZrCl}}(100 \mathrm{kBq})\right.$ in HEPES $(0.2 \mathrm{M})$ to give a $33.3 \mu \mathrm{M}$ solution of bioconjugate. This was agitated and left at room temperature for $10 \mathrm{~min}$. Radiochemical yield was determined using ITLC-SG strips spotted with $1 \mu \mathrm{L}$ of radiolabelling mixture, which were developed in a mobile phase of 0.1 $\mathrm{M}$ citrate buffer $\left(\mathrm{pH}\right.$ 5.5). For $\left[{ }^{89} \mathrm{Zr}\right] \mathrm{Zr}$-dfo-dtm-trastuzumab: $R_{\mathrm{f}}<0.1$; for unreacted $\left.{ }^{89} \mathrm{Zr}\right] \mathrm{Zr}{ }^{4+}: R_{\mathrm{f}}>0.9$. Size exclusion HPLC was also used to assess radiochemical purity. $\left.{ }^{89} \mathrm{Zr}\right] \mathrm{Zr}$-dfo-dtm-trastuzumab had a retention time of $7.75 \mathrm{~min}$, whilst unreacted $\left[{ }^{89} \mathrm{Zr}\right] \mathrm{Zr}^{4+}$ eluted at 11.58 . Near quantitative (> 99\%) radiochemical yields were achieved.

Radiolabelling of dfo-dtm-trastuzumab with $\left[{ }^{89} \mathrm{Zr}\right] \mathrm{Zr}^{4+}$ at varying concentrations of bioconjugate

The radiolabelling protocol above was repeated at bioconjugate concentrations of $16.7 \mu \mathrm{M}, 3.33 \mu \mathrm{M}, 333 \mathrm{nM}$, $33 \mathrm{nM}$, and $3 \mathrm{nM}$. Radiochemical yields were assessed by ITLC.

\section{Serum stability and target receptor affinity of $\left[{ }^{64} \mathrm{Cu}\right] \mathrm{Cu}$-sar-dtm-trastuzumab and $\left[{ }^{89} \mathrm{Zr}\right] \mathrm{Zr}$-dfo-dtm- trastuzumab}

Serum stability of $\left[{ }^{64} \mathrm{Cu}\right] \mathrm{Cu}$-sar-dtm-trastuzumab

A sample of $\left[{ }^{64} \mathrm{Cu}\right] \mathrm{Cu}^{2+}(6 \mathrm{MBq}$ in $60 \mu \mathrm{L}$ of $0.1 \mathrm{M}$ ammonium acetate) was added to sar-dtm-trastuzumab (20 $\mu \mathrm{L}$, $\sim 230 \mu \mathrm{g}, 80 \mu \mathrm{M}$, in $0.1 \mathrm{M} \mathrm{NH}_{4} \mathrm{OAc}$ ), mixed and left at room temperature for $5 \mathrm{~min}$. Radiochemical yield was assessed using ITLC and size exclusion HPLC. A sample of this radiolabelled solution was added to serum, in a 
ratio of one part radiolabelled solution to four parts serum (by volume), and incubated at $37^{\circ} \mathrm{C}$. Aliquots were taken for analysis by size exclusion HPLC at $0 \mathrm{~h}, 20 \mathrm{~h}$, and $40 \mathrm{~h}$.

\section{Serum stability of $\left[{ }^{89} \mathrm{Zr}\right] \mathrm{Zr}$-dfo-dtm-trastuzumab}

A sample of [ $\left.{ }^{89} \mathrm{Zr}\right] \mathrm{Zr}{ }^{4+}(5 \mathrm{MBq}, 25 \mu \mathrm{L}$, in $0.2 \mathrm{M} \mathrm{HEPES})$ was added to dfo-dtm-trastuzumab (160 $\mu \mathrm{L}, 81 \mu \mathrm{M}$, in 0.1 $\mathrm{M}$ ammonium acetate), mixed and left at room temperature for $10 \mathrm{~min}$. Radiochemical yield was assessed using ITLC and size exclusion HPLC. A sample of this radiolabelled solution was added to serum at incubated at $37^{\circ} \mathrm{C}$. For serum stability experiments at $5 \mathrm{~min}, 2$ days, and 4 days one part radiolabelled solution was added to four parts serum (by volume). For the longest time-point, one part radiolabelled solution was added to two parts serum (by volume) to ensure a sufficient amount of radioactivity was present within the sample for analysis after 7 days incubation. Samples were analysed by size exclusion HPLC at 5 min, 2 days, 4 days and 7 days.

\section{SKOV3 in vitro binding study of $\left[{ }^{64} \mathrm{Cu}\right] \mathrm{Cu}$-sar-dtm-trastuzumab}

SKOV3 cells were grown in T150 flasks in culture medium. Cells were aspirated and washed with PBS, then treated with trypsin to detach the cells from the flask and then washed again with PBS. The cells were resuspended in HBSS with $0.2 \%$ BSA to give $2 \times 10^{5}$ cells per tube in $250 \mu \mathrm{L}$. Trastuzumab solution $(500 \mu \mathrm{L}, 2 \mu \mathrm{M}$ - $1 \mathrm{nM}$, in HBSS with $0.2 \% \mathrm{BSA})$ was added to each tube, followed by $\left[{ }^{64} \mathrm{Cu}\right] \mathrm{Cu}$-sar-dtm-trastuzmab $(250 \mu \mathrm{L}, 1$ $\mu \mathrm{g}, 10 \mathrm{kBq}$, in HBSS with $0.2 \% \mathrm{BSA}$ ). Tubes were incubated on ice for $1 \mathrm{hr}$. The cells were washed by centrifuging at $500 \mathrm{rcf}$ for $3 \mathrm{~min}$, aspirating the supernatant, and resuspending in ice cold PBS (1 mL), centrifuging once more at $500 \mathrm{rcf}$ for $3 \mathrm{~min}$, and aspirating the supernatant. The radioactivity associated with cell pellets was counted using a Wallac 1282 Compugamma Universal Gamma Counter. Non-linear regression analysis was performed using a one site total binding fit model (Graphpad Prism 8).

\section{In vivo assessment of $\left[{ }^{64} \mathrm{Cu}\right] \mathrm{Cu}$-sar-dtm-trastuzumab}

\section{Biodistribution study of $\left[{ }^{64} \mathrm{Cu}\right] \mathrm{Cu}$-sar-dtm-trastuzumab}

The biodistribution of $\left[{ }^{64} \mathrm{Cu}\right] \mathrm{Cu}$-sar-dtm-trastuzumab was assessed in twelve 9-week-old NOD scid gamma (NSG) mice, which were purchased from Charles River UK and left to acclimatise for five days before use with ad libitum access to water and diet (PicoLab Rodent Diet 20, LabDiet, St Louis, Missouri). Mice were housed in cages of 6 equipped with Lignocel soft wood pellets, environmental enrichment, and maintained at a temperature of $20^{\circ} \mathrm{C}$ to $24{ }^{\circ} \mathrm{C}$ and $45 \%$ to $65 \%$ humidity. For injection, mice were anaesthetised by inhalation of a $3 \%$ isofluraneoxygen mixture and placed on a nose cone for maintenance with a 1.5-2.5 \% isoflurane-oxygen mixture. The mice were injected intravenously (tail vein) with $\sim 1.5 \mathrm{MBq}(150 \mu \mathrm{g}, 150 \mu \mathrm{L}$ in $0.9 \%$ saline). Mice were housed individually in grid floor cages after injection. Biodistribution mice were placed in three groups $(n=4)$ which were culled under anaesthesia at $2 \mathrm{~h}, 24 \mathrm{~h}$, or 48 hours post injection by cervical dislocation, followed by tail nick to ensure cessation of circulation. Organs were harvested, washed in PBS, dried briefly, and then placed in gamma counter tubes for weighing and radioactivity counting. The radioactivity associated with each tube was counted using a Wallac 1282 Compugamma Universal Gamma Counter. This data was processed to calculate the \% injected dose $\mathrm{g}^{-1}\left(\% \mathrm{ID} \mathrm{g}^{-1}\right)$.

\section{PET imaging study of $\left[{ }^{64} \mathrm{Cu}\right] \mathrm{Cu}$-sar-dtm-trastuzumab}

An in vivo PET imaging study was carried out on two 9-week-old NSG mice which were purchased from Charles River U2 $\mathrm{K}$ and left to acclimatise for five days before use with ad libitum access to water and diet. PET images were acquired in a nanoScan ${ }^{\circledR}$ in vivo pre-clinical PET/CT imager (Mediso, Hungary). The mice were anaesthetised by inhalation of a $3 \%$ isoflurane-oxygen mixture and placed on a nose cone for maintenance with a 1.5-2.5\% isoflurane-oxygen mixture. These mice were then injected intravenously (via tail vein) with $\left[{ }^{64} \mathrm{Cu}\right] \mathrm{Cu}$ - 
sar-dtm-trastuzumab $2.5 \mathrm{MBq}(250 \mu \mathrm{g}, 140 \mu \mathrm{L}$ in $0.9 \%$ saline). PET acquisition was started at $1 \mathrm{~h}$ post-injection ( $60 \mathrm{~min} \mathrm{scan)}$ and scans were repeated at $23 \mathrm{~h} \mathrm{(60} \mathrm{min} \mathrm{scan),} \mathrm{and} 46 \mathrm{~h} \mathrm{(120} \mathrm{min} \mathrm{scan)} \mathrm{post} \mathrm{injection.} \mathrm{The} \mathrm{scanner}$ bed was maintained at $37{ }^{\circ} \mathrm{C}$, and respiration monitoring was conducted throughout the scan. Scans were acquired at 1:5 coincidence mode and 5-ns coincidence time window. Images were reconstructed using TeraTomo 3D reconstruction (Mediso) with 4 iterations, 6 subsets, 1-3 coincidence mode, voxel sized $0.4 \mathrm{~mm}$ (isotropic), energy window 400-600 keV with attenuation and decay correction.

\section{Ex vivo serum stability}

Upon confirmation of death, $\sim 200 \mu \mathrm{L}$ of blood was harvested from each mouse by cardiac puncture. One drop was placed aside for biodistribution study whilst the rest was placed in a vet tube with gentle agitation and set aside for 1 hour. Vet tubes were centrifugated at $4000 \mathrm{rcf}$ for 12 minutes. The serum was aspirated and analysed by size exclusion HPLC and SDS-PAGE (as described above). 
Figures

(a)

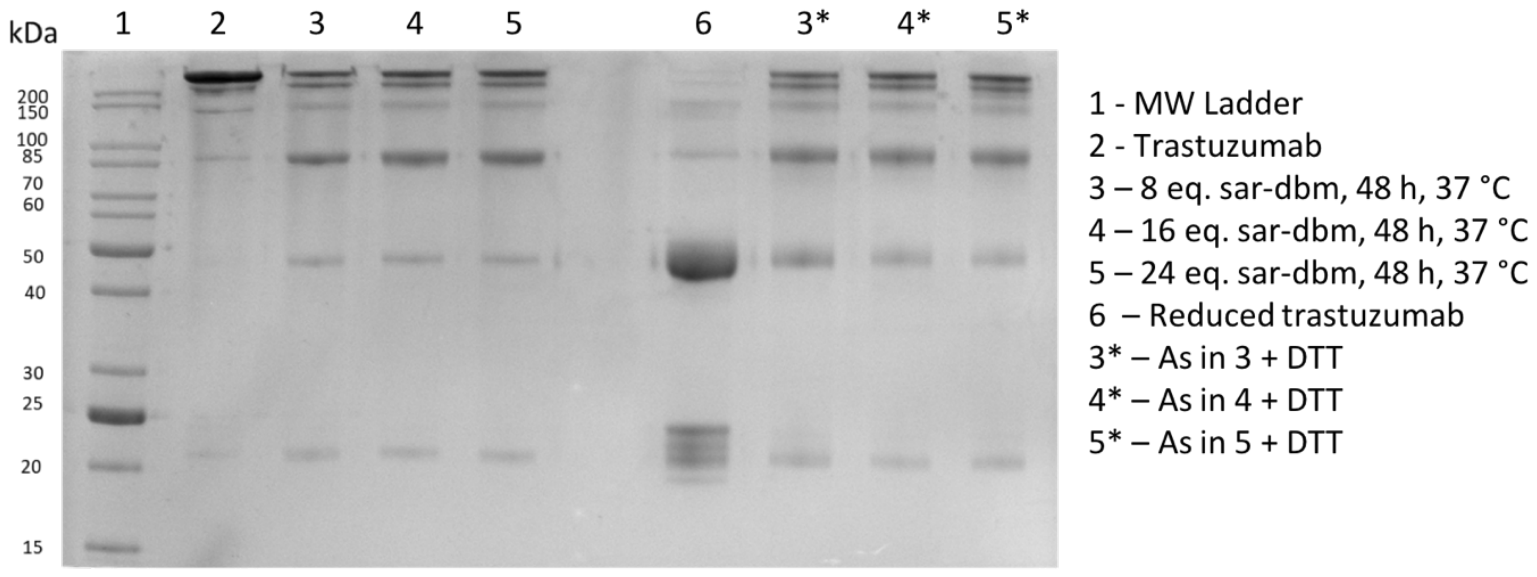

(b)

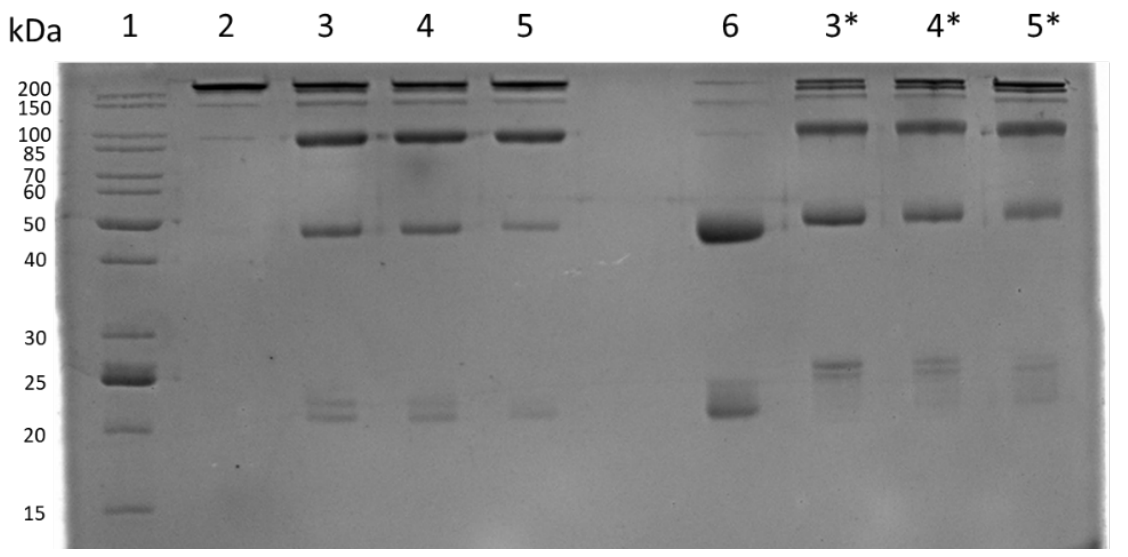

1 - MW Ladder

2 - Trastuzumab

3 - 8 eq. sar-dbm, 5 min, $37^{\circ} \mathrm{C}$

4 - 8 eq. sar-dbm, $24 \mathrm{~h}, 37^{\circ} \mathrm{C}$

5 - 8 eq. sar-dbm, 48 h, $37^{\circ} \mathrm{C}$

6 - Reduced trastuzumab

3* - As in 3 + DTT

$4^{*}$ - As in $4+$ DTT

$5^{*}$ - As in $5+$ DTT

Figure S1. (a) The conjugation reaction between reduced trastuzumab and varying equivalents of sar-dbm was monitored by SDS-PAGE. Conjugation products were also analysed using reducing SDS-PAGE conditions: dithiothreitol (DTT) was incubated with the antibody conjugate prior to running the SDS-PAGE. Using 8 equivalents of sar-dbm resulted in dithiol rebridging. With increasing equivalents of sar- $\mathrm{dbm}$, improvements were negligible. Comparison of lanes 3-5 with lanes $3^{*}-5^{*}$ indicated that the bioconjugates were stable towards DTT mediated degradation. (b) The conjugation reaction between reduced trastuzumab and sar-dbm was monitored over time by SDS-PAGE. Thiol substitution to give bridged dithiomaleimide conjugates proceeded rapidly (within 5 min, lane 3), as evidenced by the appearance of re-bridged "full" and "half" antibody constructs. Increased incubation time $(24-48 \mathrm{~h}$, lanes 4,5$)$ did not significantly increase the amounts of these species. However, full hydrolysis of dithiomaleimide conjugates to stable dithiomaleamic acid conjugates required $>5$ min (Lane $3^{*}$ ); to ensure full hydrolysis, the conjugate was incubated for $48 \mathrm{~h}$ at $37^{\circ} \mathrm{C}$ and $\mathrm{pH} 8.5$ (lanes $4^{*}, 5^{*}$ ). 


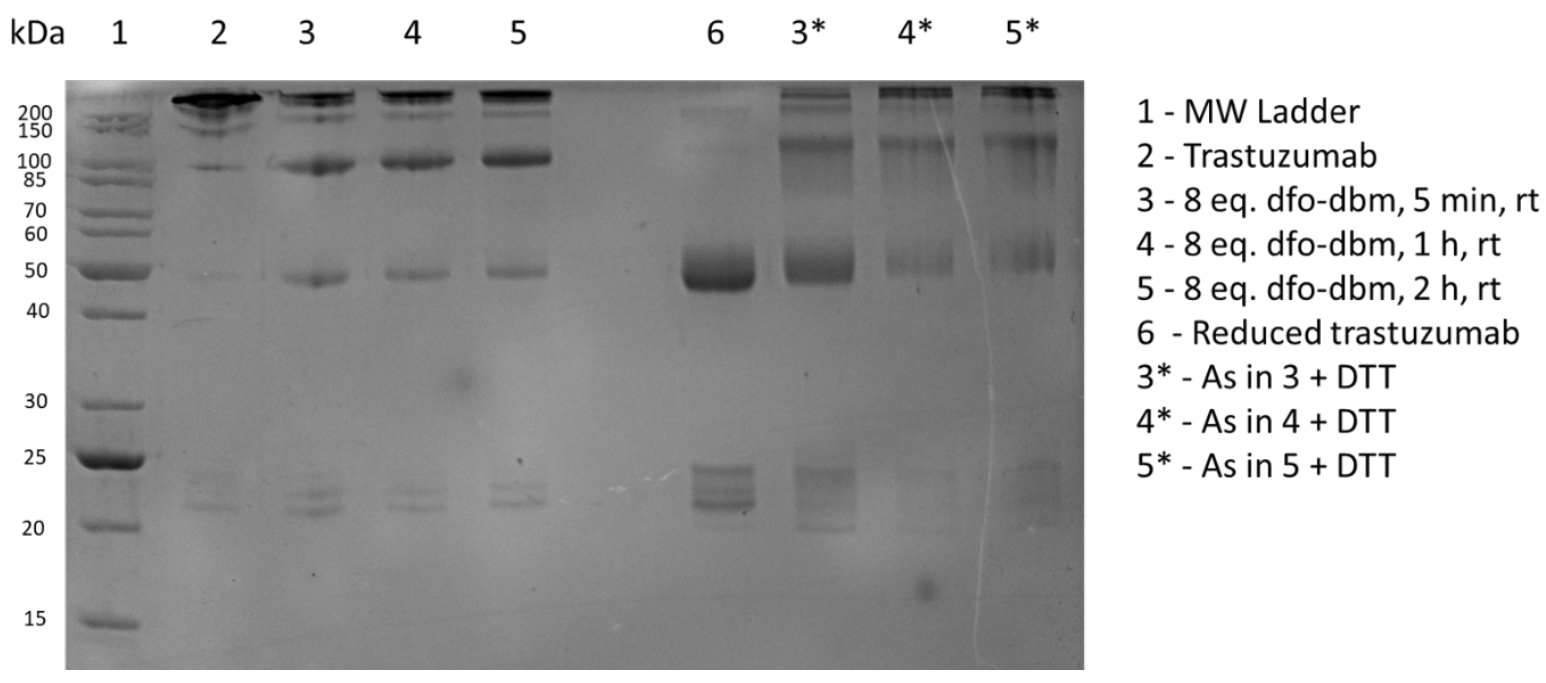

Figure S2. The conjugation reaction between reduced trastuzumab and dfo-dbm was monitored over time by SDS-PAGE (lanes 3-5). Conjugation products were also analysed using reducing SDS-PAGE conditions: dithiothreitol (DTT) was incubated with the antibody conjugate prior to running the SDS-PAGE (lanes $3^{*}-5^{*}$ ). Thiol substitution to give bridged dithiomaleimide conjugates proceeded rapidly (within $5 \mathrm{~min}$, lane 3), as evidenced by the appearance of re-bridged "full" and "half" antibody constructs. Increased incubation time $(1 \mathrm{~h}-2 \mathrm{~h}$, lanes 4,5$)$ did not significantly increase the amounts of these species. However, full hydrolysis of dithiomaleimide conjugates to stable dithiomaleamic acid conjugates required $>5$ min (lane $3^{*}$ ); to ensure full hydrolysis, the conjugate was incubated for $2 \mathrm{~h}$ at $37^{\circ} \mathrm{C}$ and $\mathrm{pH} 8.5$ (lanes $4^{*}, 5^{*}$ ).

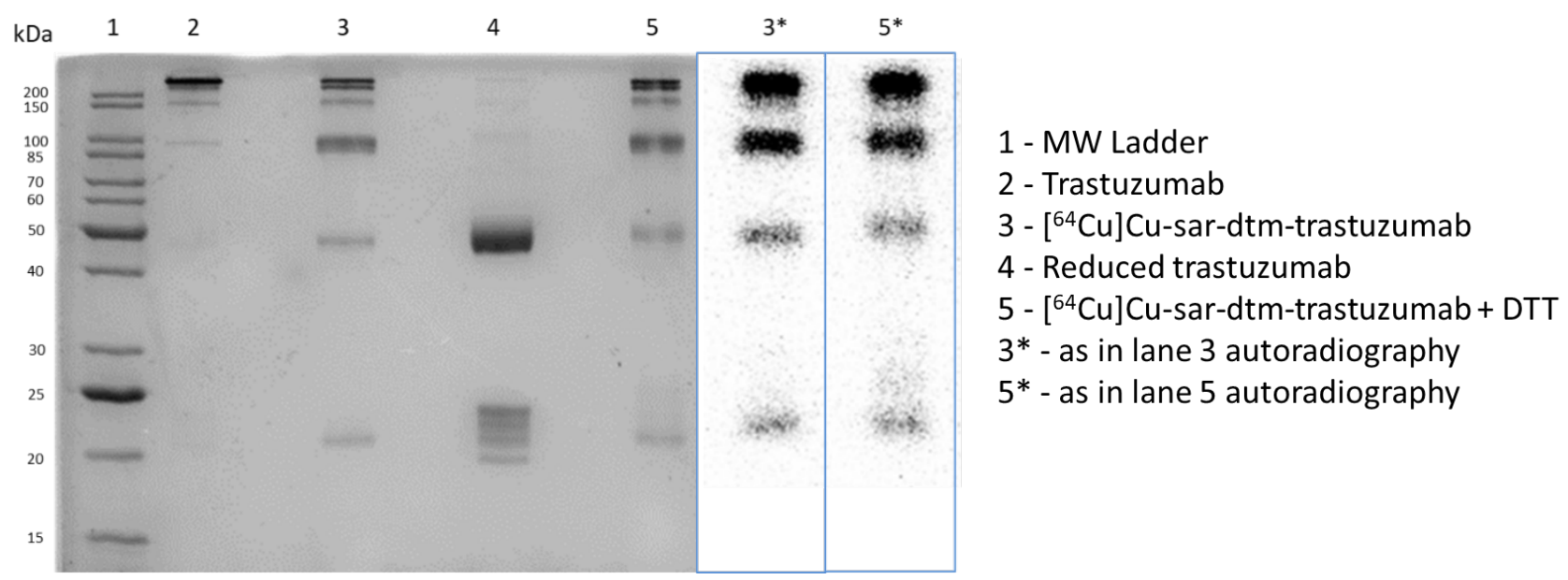

Figure S3. SDS-PAGE bright light image (left) and autoradiography image (right) of $\left[{ }^{64} \mathrm{Cu}\right] \mathrm{Cu}$-sar-dtm-trastuzumab. The radioactivity signal from the radiolabelled immunoconjugate was coincident with the stained protein bands corresponding to "full" and "half" antibody (lanes 3, 3*). The radiolabelled bioconjugate was stable under reducing conditions where 100 equivalents of DTT were added, as shown by the coincident radioactivity signal and stained protein bands (lanes 5 and $5^{*}$ ). 


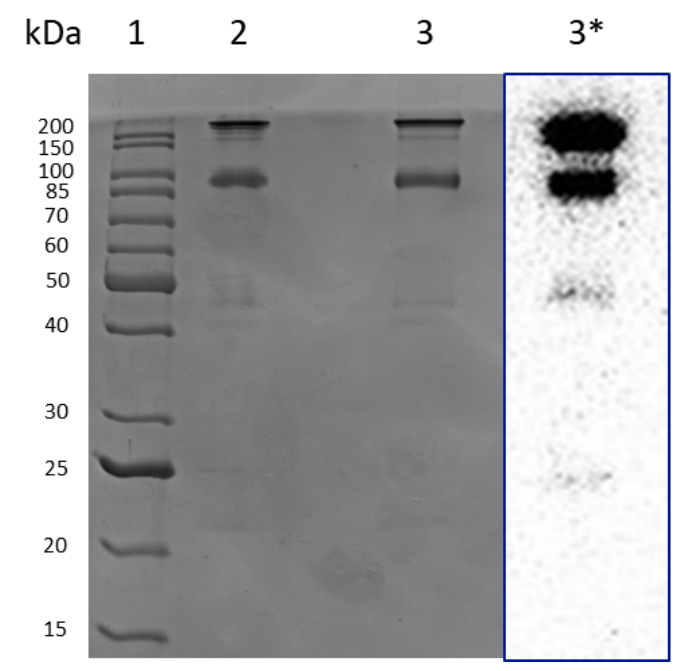

1 - MW Ladder

2 - dfo-dtm-trastuzumab

3 - $\left[{ }^{89} \mathrm{Zr}\right] \mathrm{Zr}$-dfo-dtm-trastuzumab

$3^{*}$ - as in lane 3 autoradiography

Figure S4. SDS-PAGE bright light image (left) and autoradiography image (right) of [ ${ }^{89} \mathrm{Zr}$ ]Zr-dfo-dtm-trastuzumab. The radioactivity signal from the radiolabelled immunoconjugate was coincident with the stained protein bands corresponding to "full" and "half" antibody.

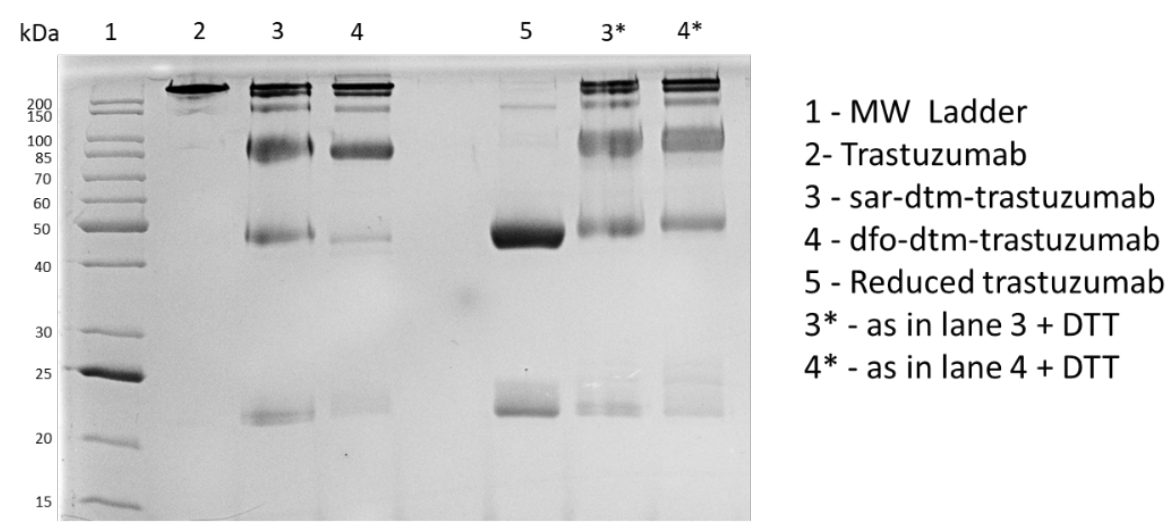

Figure S5. SDS-PAGE of sar-dtm-trastuzumab and dfo-dtm-trastuzumab (lanes 3 and 4). Dithiomaleimide hydrolysis was complete within $48 \mathrm{~h}$ at $37^{\circ} \mathrm{C}$ as shown by the bioconjugates' stability under denaturing conditions in the presence of 100 equivalents of DTT (lanes $3^{*}$ and $4 *$ ). 
(a)

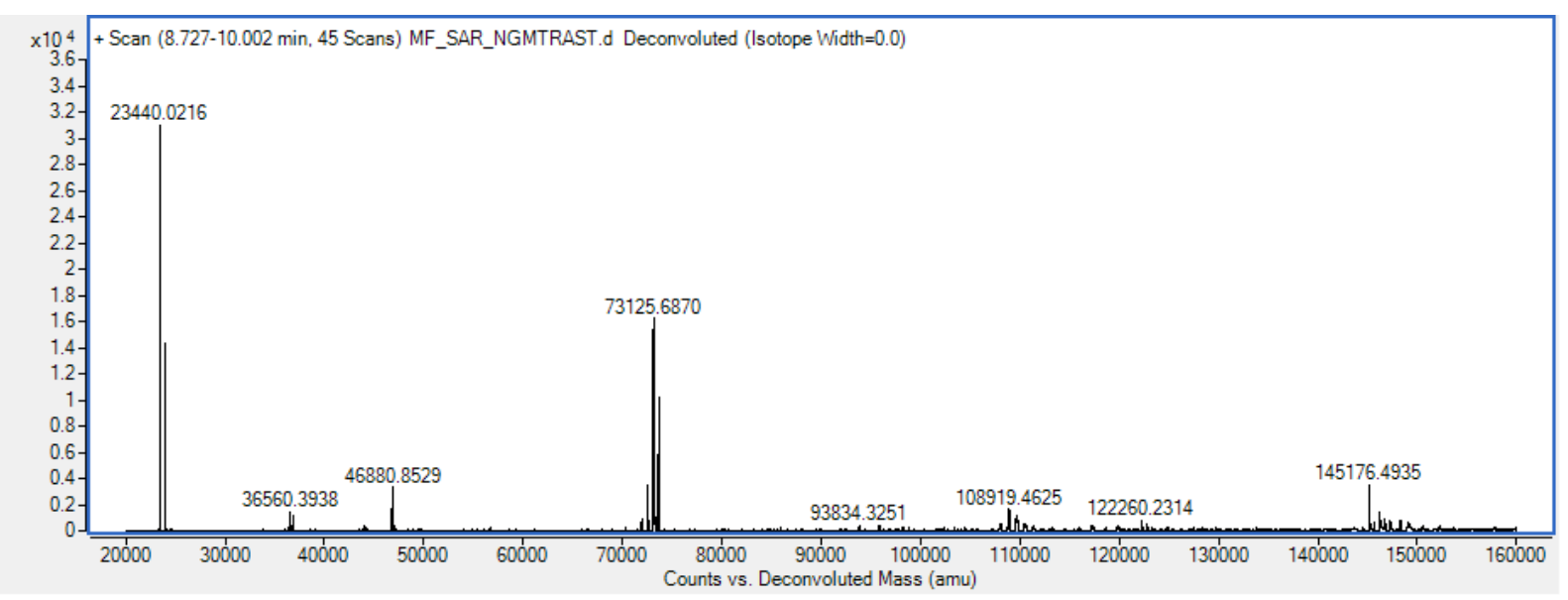

(b) $\quad x 10^{4}+$ Scan (8.727-10.002 min, 45 Scans) MF_SAR_NGMTRAST.d Deconvoluted (Isotope Width $=0.0$ )

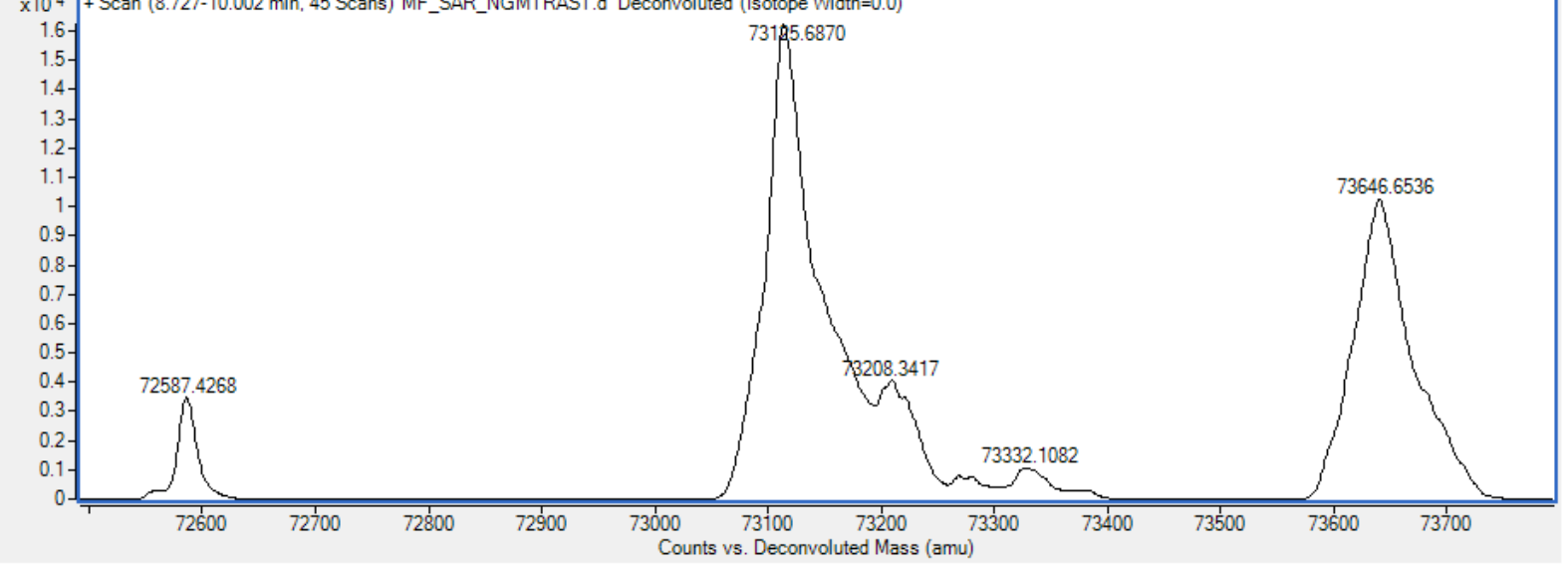

(c)

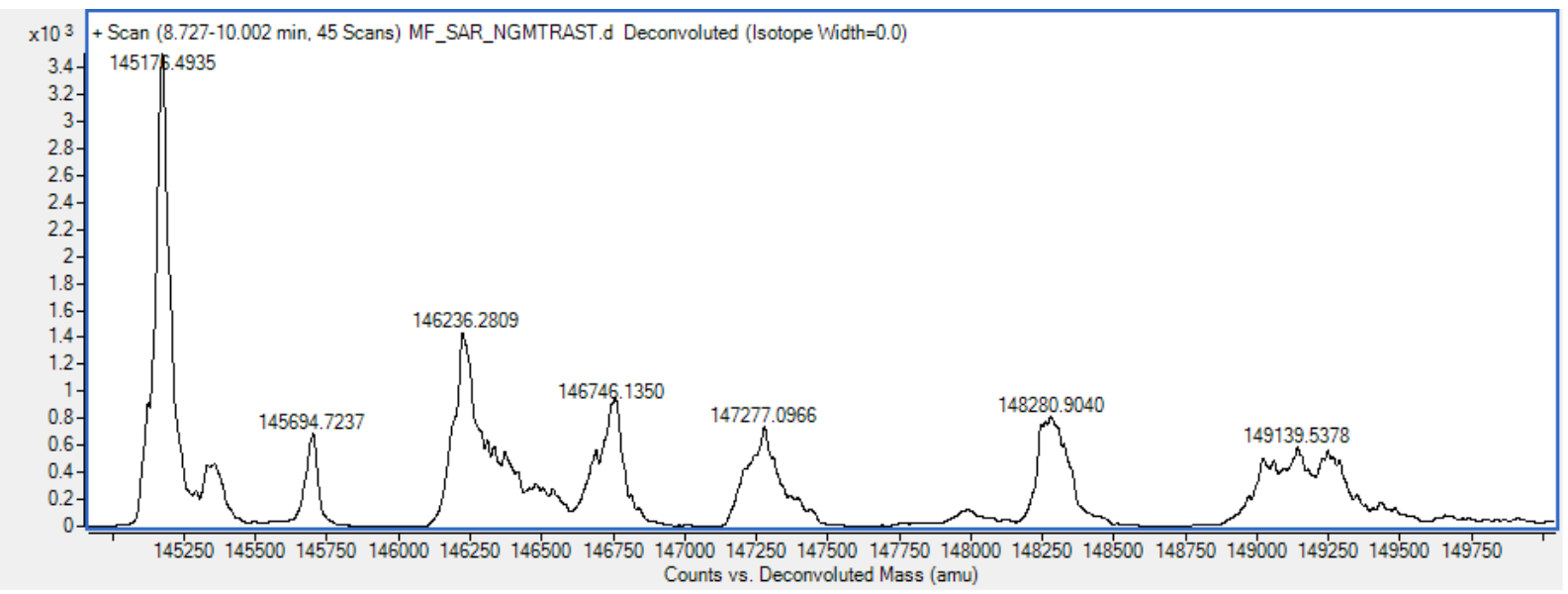

Figure S6. High resolution ESI deconvoluted mass spectrum of sar-dtm-trastuzumab: (a) full spectrum, (b) expanded view of the region associated with "half" antibody conjugates, and (c) expanded view of the region associated with "full" antibody conjugates (see Table S2 for assignments, page 6). 
(a)

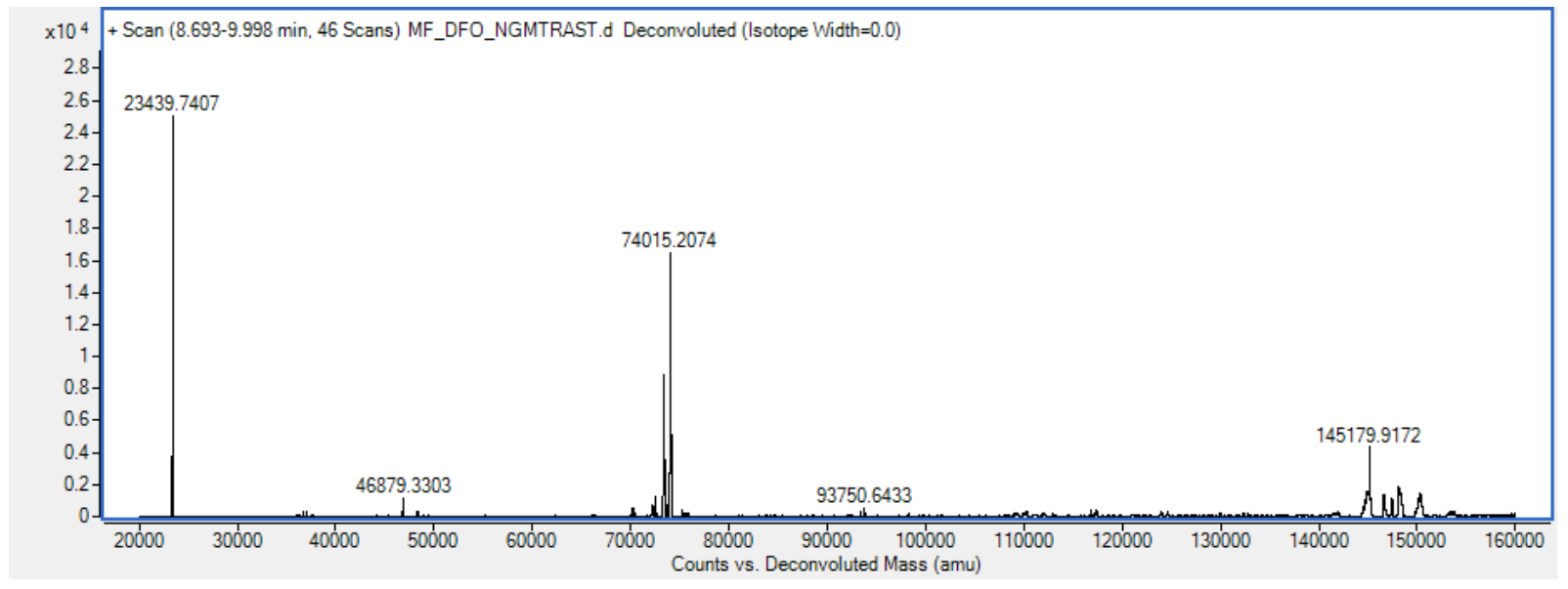

(b)

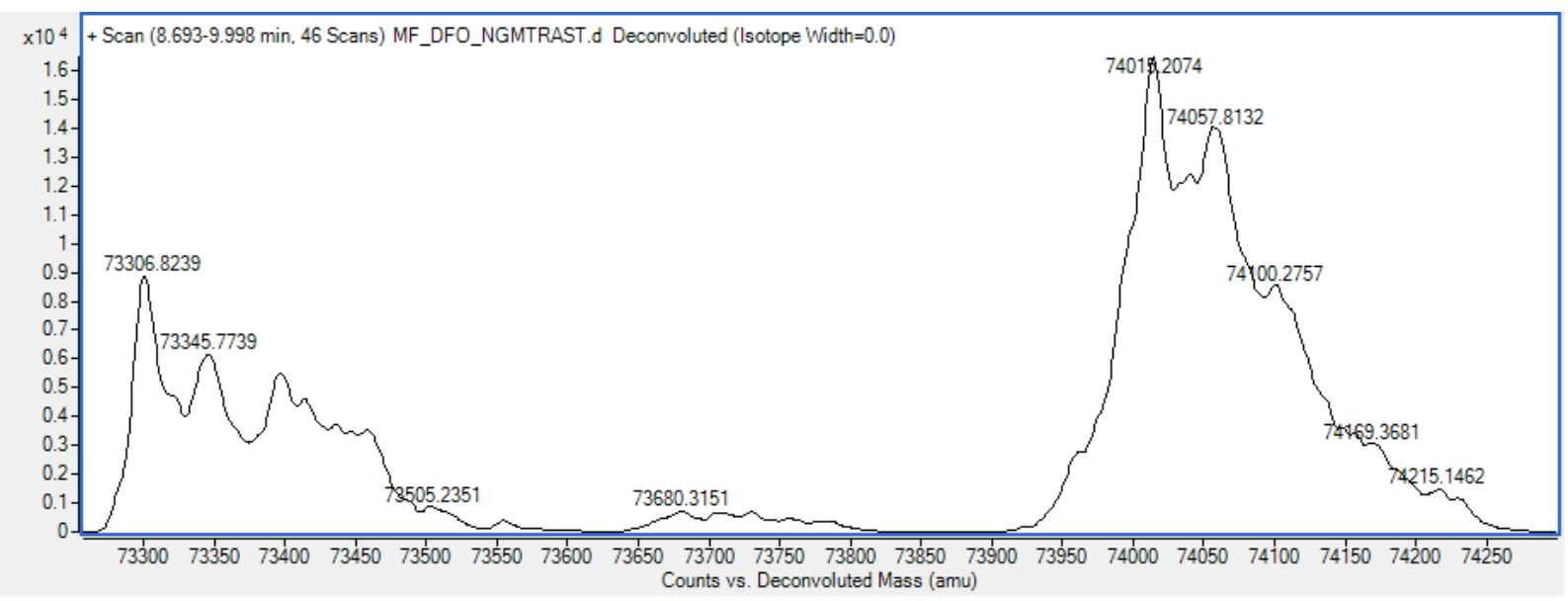

(c) $\times 103+$ Scan (8.693-9.998 min, 46 Scans) MF_DFO_NGMTRAST.d Deconvoluted (Isotope Width $=0.0)$

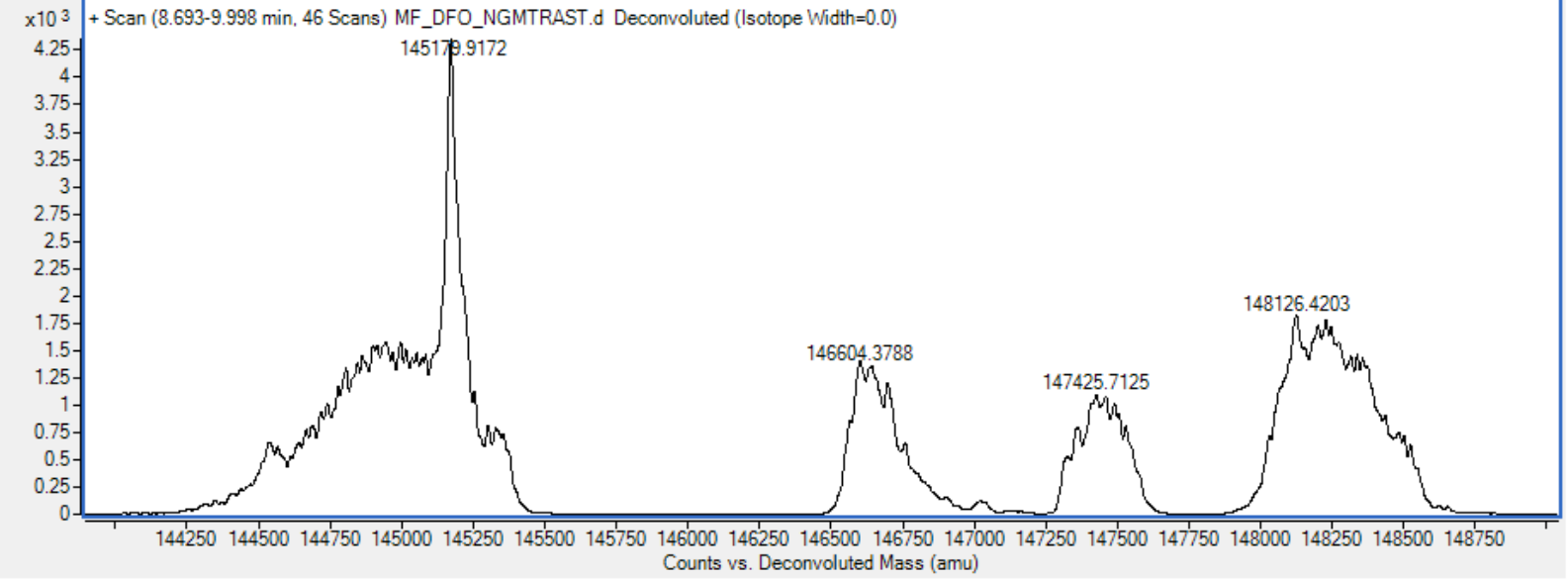

Figure S7. High resolution ESI deconvoluted mass spectrum of dfo-dtm-trastuzumab: (a) full spectrum, (b) expanded view of the region associated with "half" antibody conjugates, and (c) expanded view of the region associated with "full" antibody conjugates (see Table S2 for assignments, page 6). 


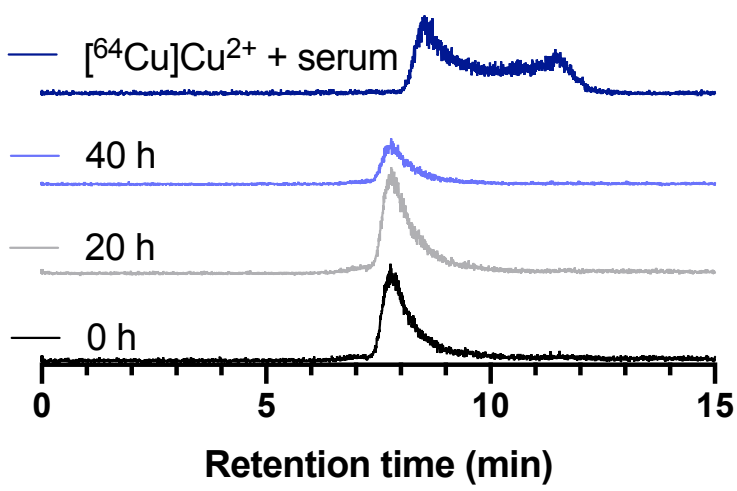

Figure S8. Size exclusion HPLC chromatograms of [ $\left.{ }^{64} \mathrm{Cu}\right] \mathrm{Cu}$-sar-dtm-trastuzumab after incubation with human serum for 20 $\mathrm{h}$ and $40 \mathrm{~h}$. Each chromatogram shows a single radioactive signal, with the retention time of each signal corresponding to $\left[{ }^{64} \mathrm{Cu}\right] \mathrm{Cu}$-sar-dtm-trastuzumab (retention time $=7.8 \mathrm{~min}$ ). When $\left[{ }^{64} \mathrm{Cu}\right] \mathrm{Cu}^{2+}$ was incubated with human serum for $20 \mathrm{~h}$ at 37 ${ }^{\circ} \mathrm{C}$, two signals were observed: the first signal at 8.5 min corresponds to $\left[{ }^{64} \mathrm{Cu}\right] \mathrm{Cu}^{2+}$ complexed by serum protein; the second peak at 11.6 min corresponds to a lower molecular weight species or unreacted $\left[{ }^{64} \mathrm{Cu}\right] \mathrm{Cu}^{2+}$.

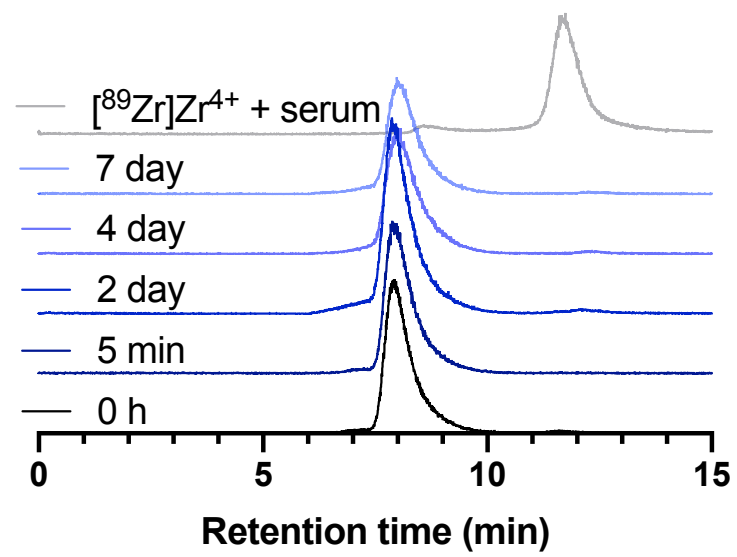

Figure 59. Size exclusion HPLC chromatograms of [ $\left.{ }^{89} \mathrm{Zr}\right] \mathrm{Zr}$-dfo-dtm-trastuzumab after incubation with human serum, over the course of 7 days. Each chromatogram shows a single radioactive signal, with the retention time of each signal corresponding to [ ${ }^{89} \mathrm{Zr}$ ]Zr-dfo-dtm-trastuzumab (retention time $=7.8 \mathrm{~min}$ ). When $\left.{ }^{89} \mathrm{Zr}\right] \mathrm{Zr}{ }^{4+}$ was incubated with human serum, two signals were observed: the first signal at $8.5 \mathrm{~min}$ corresponds to [ $\left.{ }^{89} \mathrm{Zr}\right] \mathrm{Zr}^{4+}$ complexed by serum protein; the second peak at $11.8 \mathrm{~min}$ corresponds to a lower molecular weight species or unreacted $\left[{ }^{89} \mathrm{Zr}\right] \mathrm{Zr}^{4+}$.
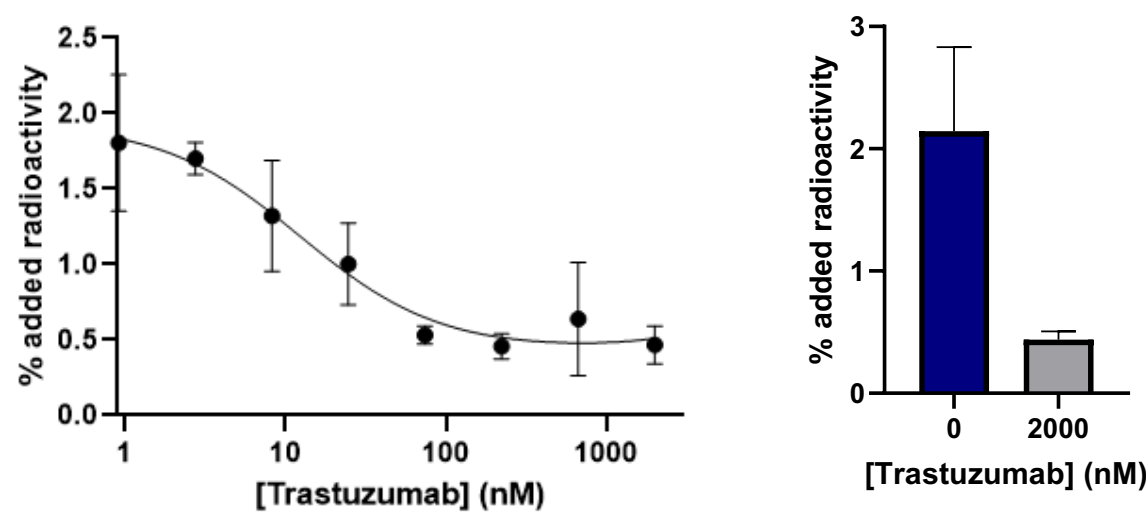

[Trastuzumab] (nM)

Figure S10. Cell binding study of $\left[{ }^{64} \mathrm{Cu}\right] \mathrm{Cu}$-sar-dtm-trastuzumab with HER2-positive SKOV3 cells. $\left[{ }^{64} \mathrm{Cu}\right] \mathrm{Cu}$-sar-dtmtrastuzumab binds to HER2-positive SKOV3 cells, and this can be inhibited by increasing concentrations of native trastuzumab. Here, the $\%$ of added $\left[{ }^{64} \mathrm{Cu}\right] \mathrm{Cu}$-sar-dtm-trastuzumab radioactivity associated with the cell pellet is plotted against the concentration of added trastuzumab. A bar chart has been used to show the difference in cell uptake of $\left.{ }^{64} \mathrm{Cu}\right] \mathrm{Cu}$ sar-dtm-trastuzumab at the lowest $(0 \mathrm{nM})$ and highest $(2000 \mathrm{nM})$ trastuzumab concentrations tested. Error bars show standard deviation. Binding studies were carried out in experimental triplicate $(n=3, n=3, n=2)$. 

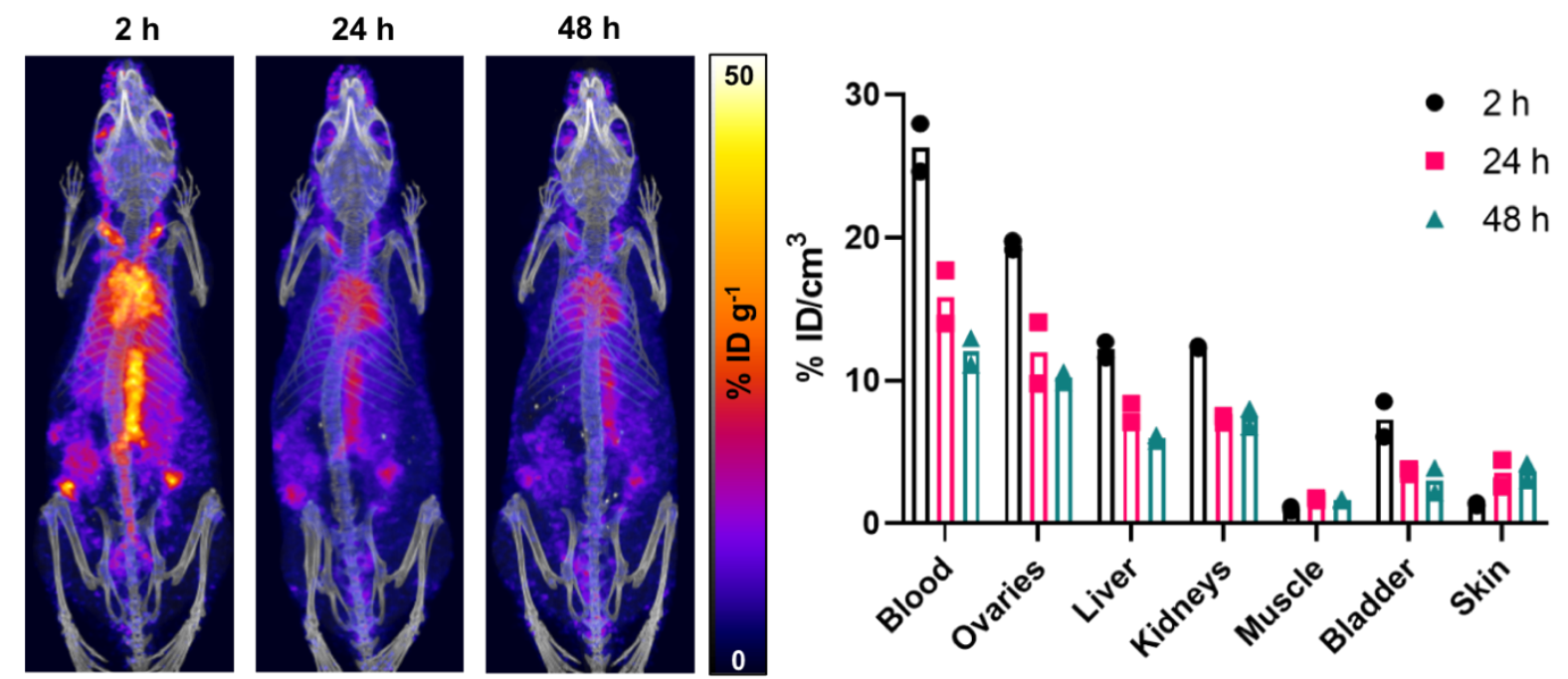

Figure S11. Left, maximum intensity projections of mice injected with $\left[{ }^{64} \mathrm{Cu}\right] \mathrm{Cu}$-sar-dtm-trastuzumab at $2 \mathrm{~h}, 24 \mathrm{~h}$, and $48 \mathrm{~h}$ post injection. Right, regions of interest were selected on VivoQuant (inviCRO, LLC, Boston, USA), and percentage injected dose per millilitre $(\% \mathrm{ID} / \mathrm{mL})$ were calculated for each. Bars show mean values $(n=2)$, individual data points are plotted.

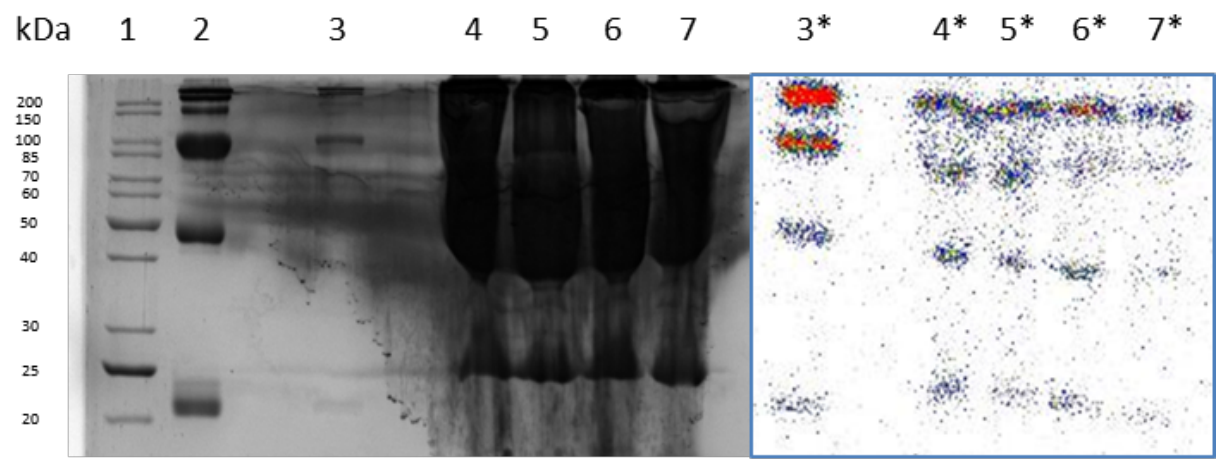

1 - MW Ladder

2 - sar-dtm-trastuzumab

3 - $\left[{ }^{64} \mathrm{Cu}\right] \mathrm{Cu}$-sar-dtm-trastuzumab

4 - Serum mouse 1

5 - Serum mouse 2

6 - Serum mouse 3

7 - Serum mouse 4

$3^{*}$ - As in lane 3 autoradiography 4* - As in lane 4 autoradiography

(b)

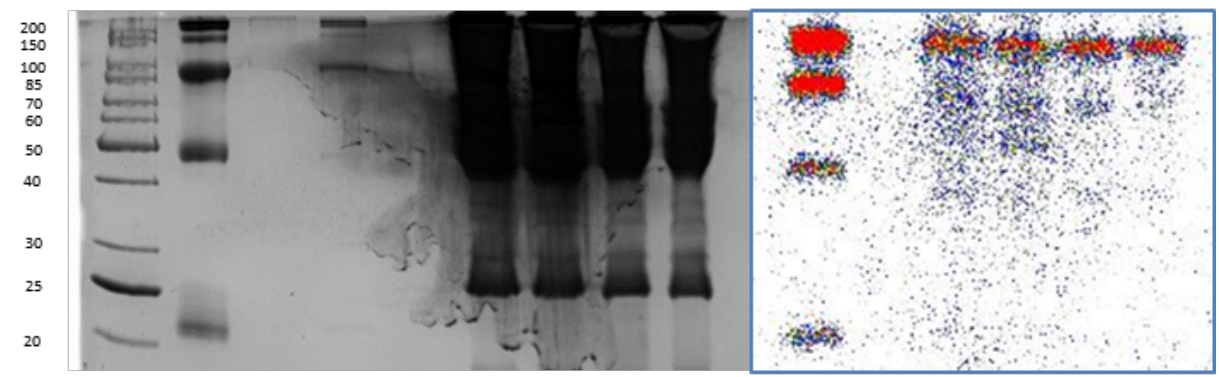

5* - As in lane 5 autoradiography 6* - As in lane 6 autoradiography 7* - As in lane 7 autoradiography

(c)

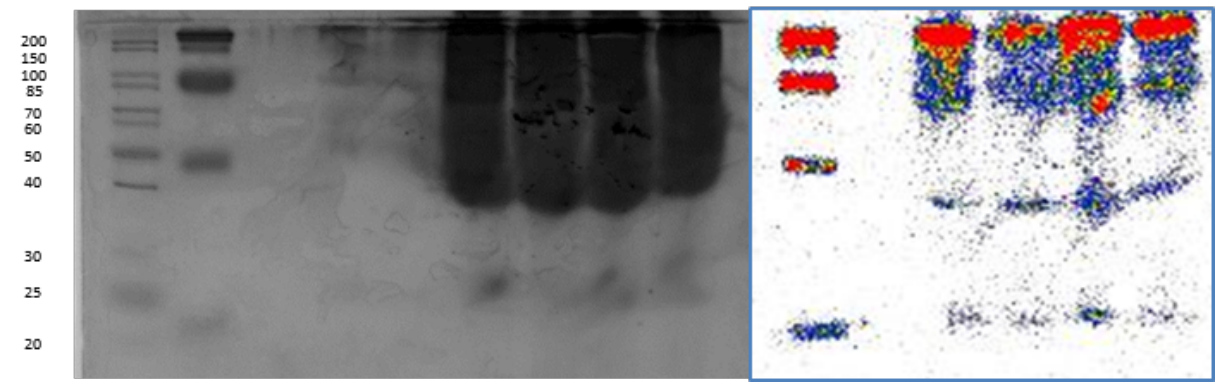

Figure S12. SDS-PAGE analysis of mouse serum after injection with $\left[{ }^{64} \mathrm{Cu}\right] \mathrm{Cu}$-sar-dtm-trastuzumab, (left) bright light images, (right) autoradiography images. (a) $2 \mathrm{~h}$ post-injection, (b) $24 \mathrm{~h}$ post-injection, (c) $48 \mathrm{~h}$ post-injection. 


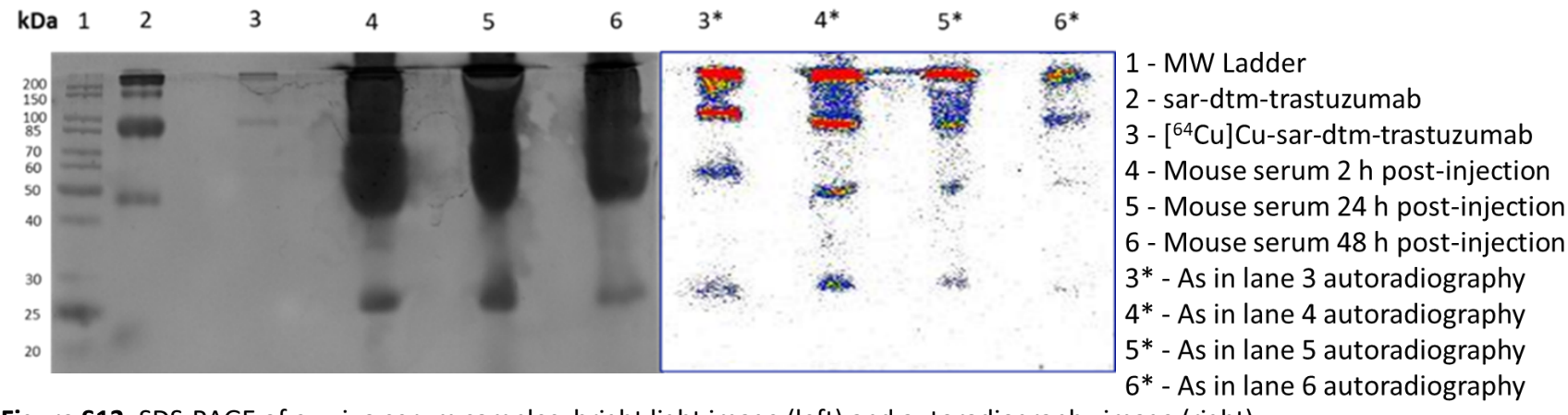

Figure S13. SDS-PAGE of ex-vivo serum samples, bright light image (left) and autoradiography image (right).

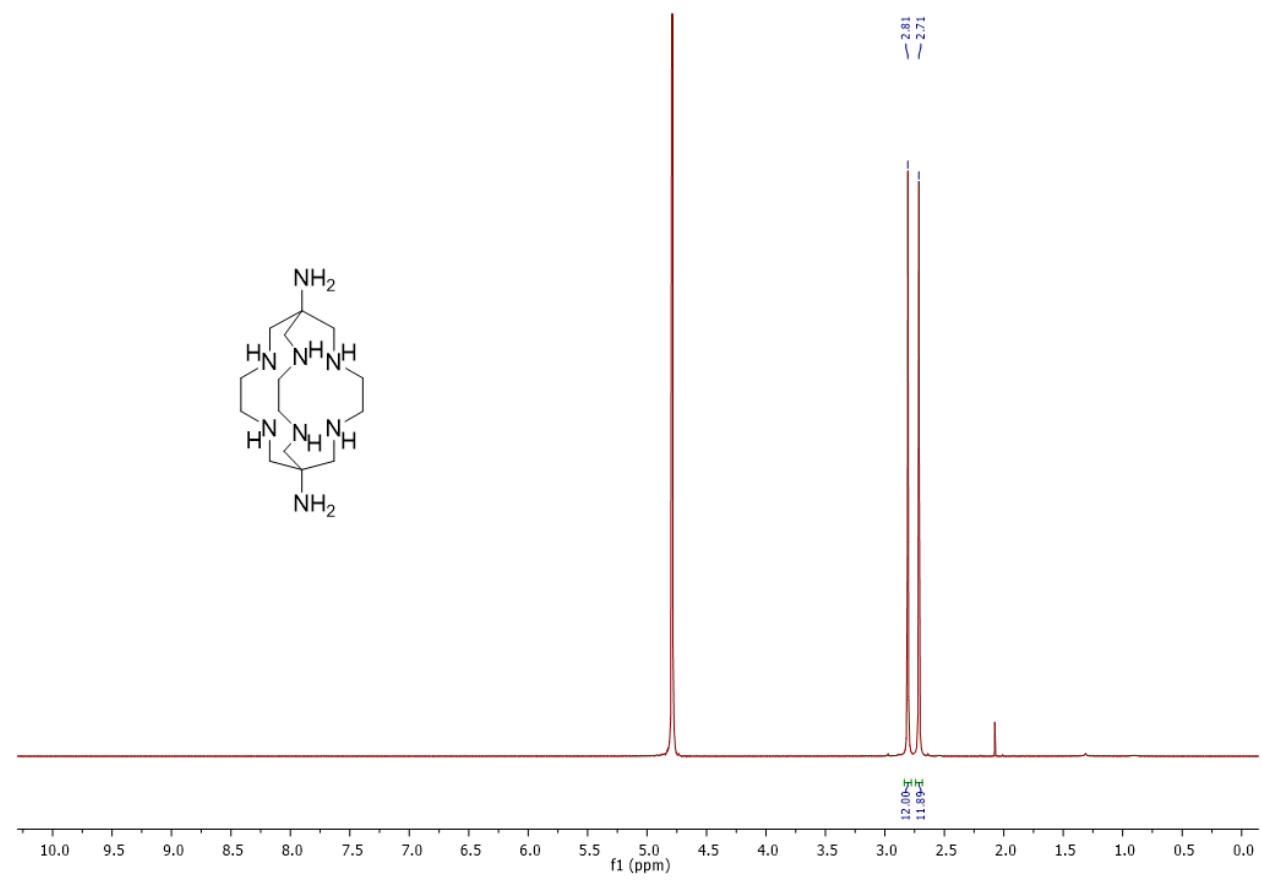

Figure S14. ${ }^{1} \mathrm{H}$ NMR spectrum for $\left(\mathrm{NH}_{2}\right)_{2} \operatorname{sar}\left(\mathrm{D}_{2} \mathrm{O}, 400 \mathrm{MHz}\right)$. 


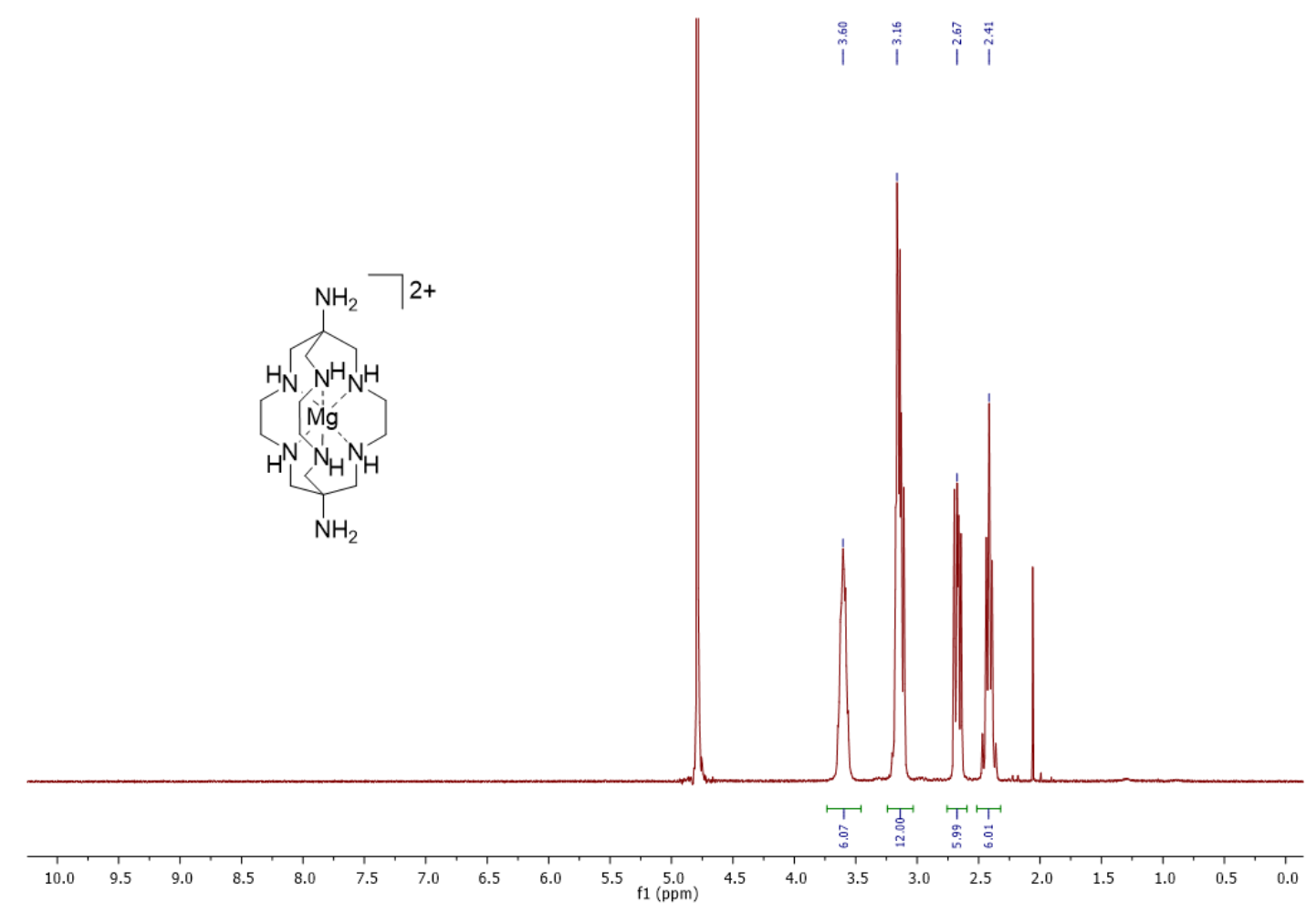

Figure S15. ${ }^{1 \mathrm{H}} \mathrm{NMR}$ spectrum for $\left[\mathrm{Mg}\left(\mathrm{NH}_{2}\right)_{2} \mathrm{Sar}\right]\left(\mathrm{CF}_{3} \mathrm{SO}_{3}\right)_{2}\left(\mathrm{D}_{2} \mathrm{O}, 400 \mathrm{MHz}\right)$.

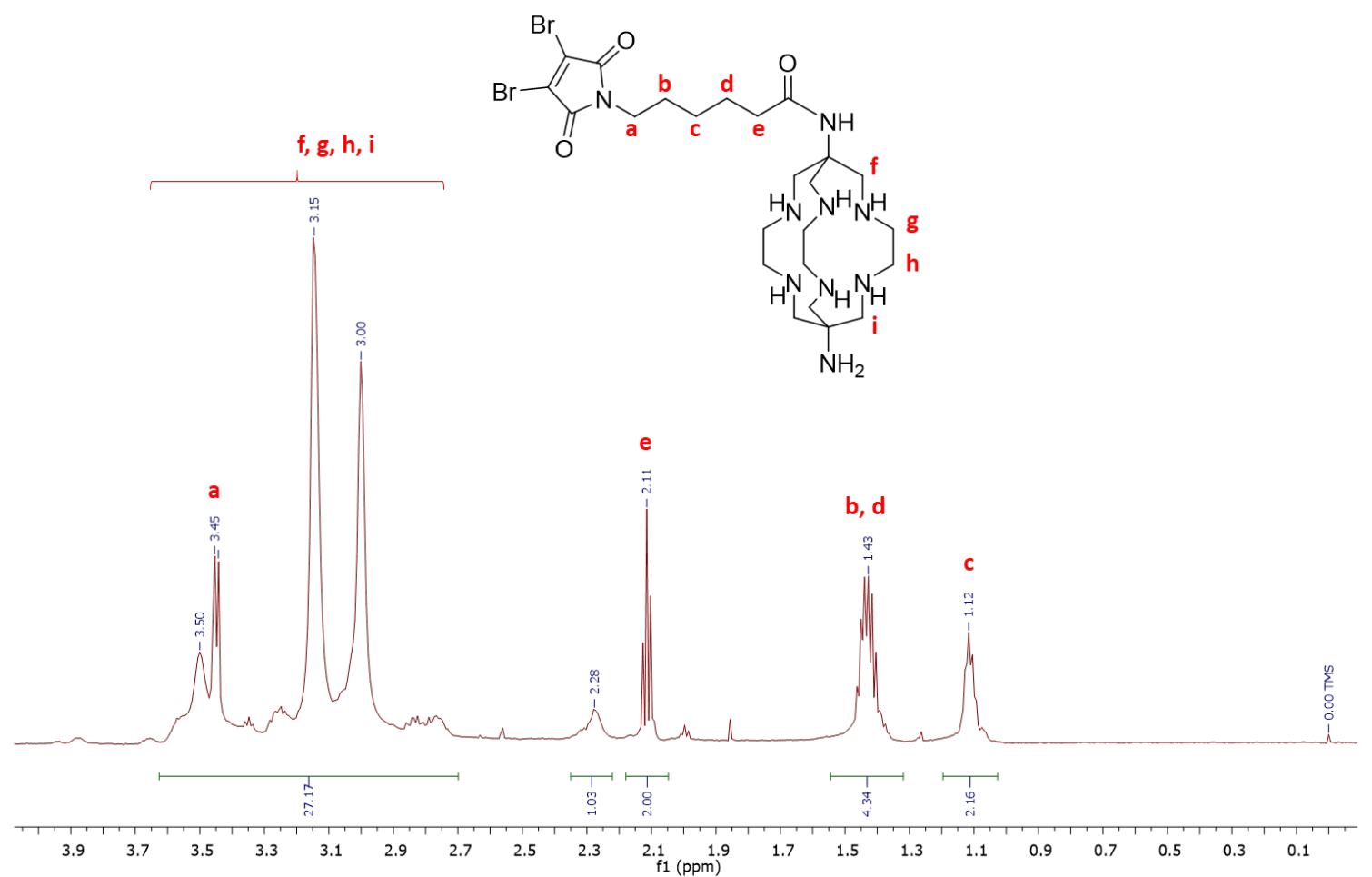

Figure S16. ${ }^{1} \mathrm{H}$ NMR spectrum for sar-dbm (3) $\left(\mathrm{D}_{2} \mathrm{O}, 700 \mathrm{MHz}\right)$. 


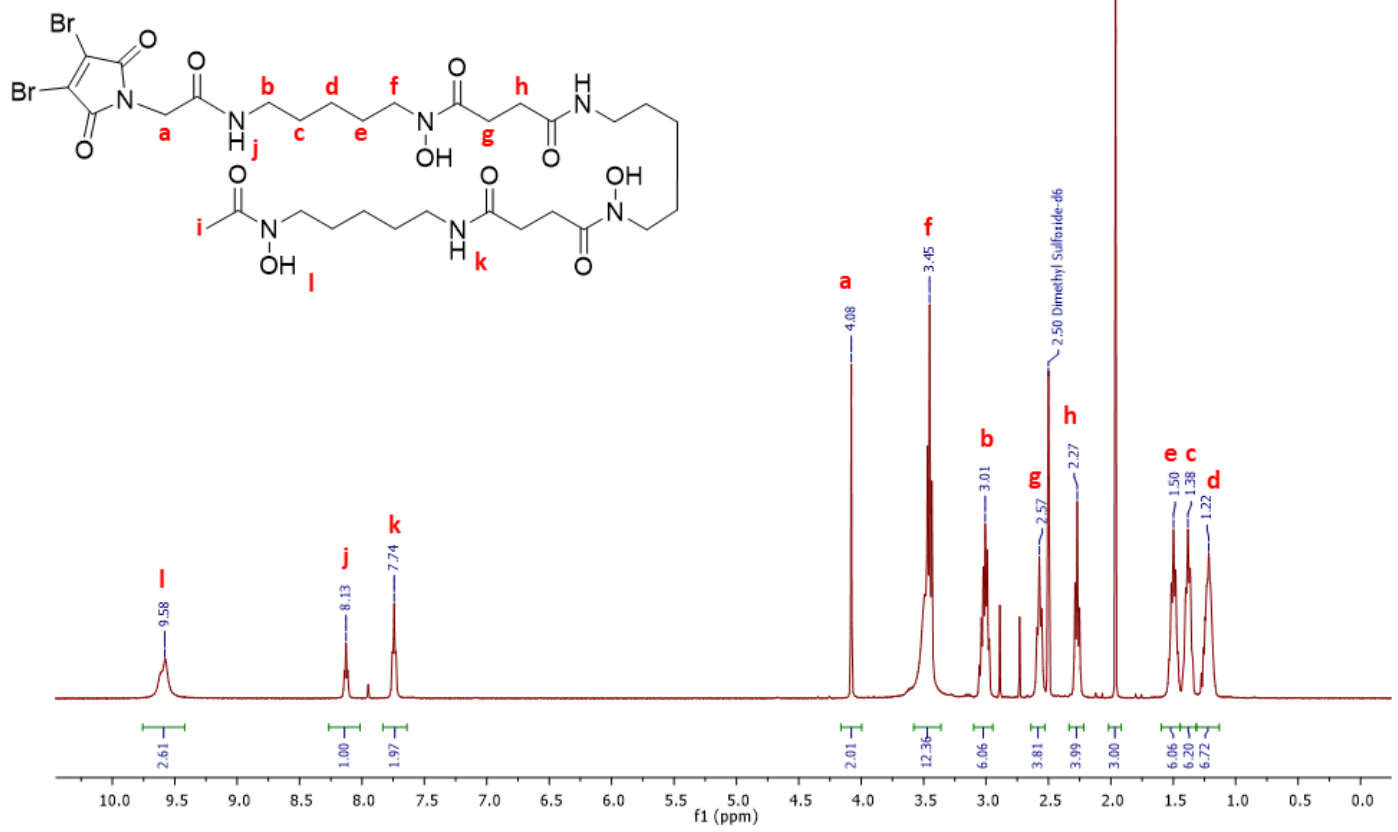

Figure S17. ${ }^{1} \mathrm{H}$ NMR spectrum for dfo-dbm (6) (DMSO- $\mathrm{d}_{6}, 400 \mathrm{MHz}$ ). The similar chemical environment of the atoms along the DFO pentyl and ethyl chains resulted in coincident resonances at $400 \mathrm{MHz}$.

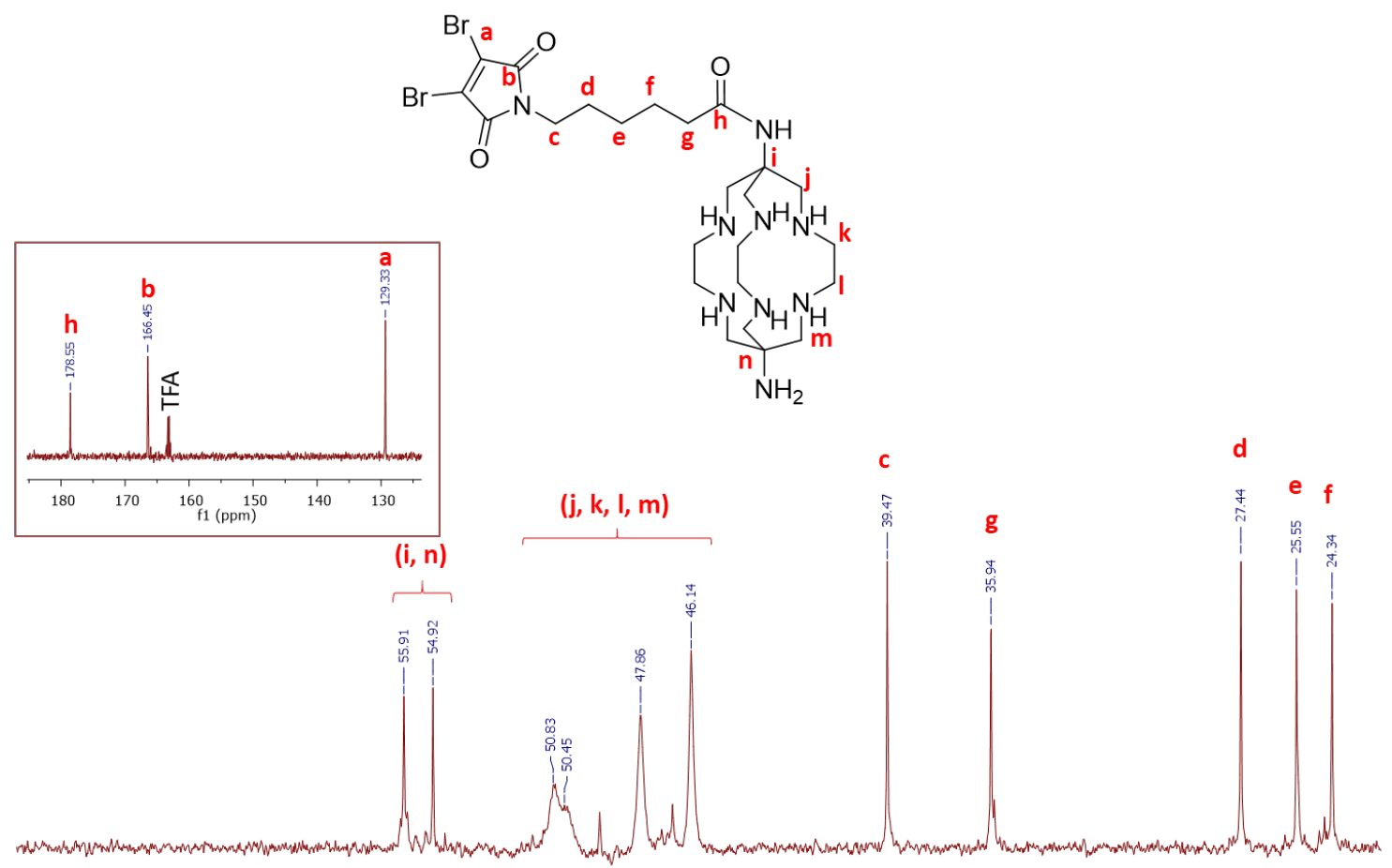

$\begin{array}{llllllllllll}68 & 66 & 64 & 62 & 60 & 58 & 56 & 54 & 52 & 50 & 48 & \begin{array}{c}46 \\ \mathrm{f} 1(\mathrm{ppm})\end{array}\end{array}$

Figure S18. ${ }^{13} \mathrm{C}$ NMR spectrum for sar-dbm (3) $\left(\mathrm{D}_{2} \mathrm{O}, 175 \mathrm{MHz}\right)$. 


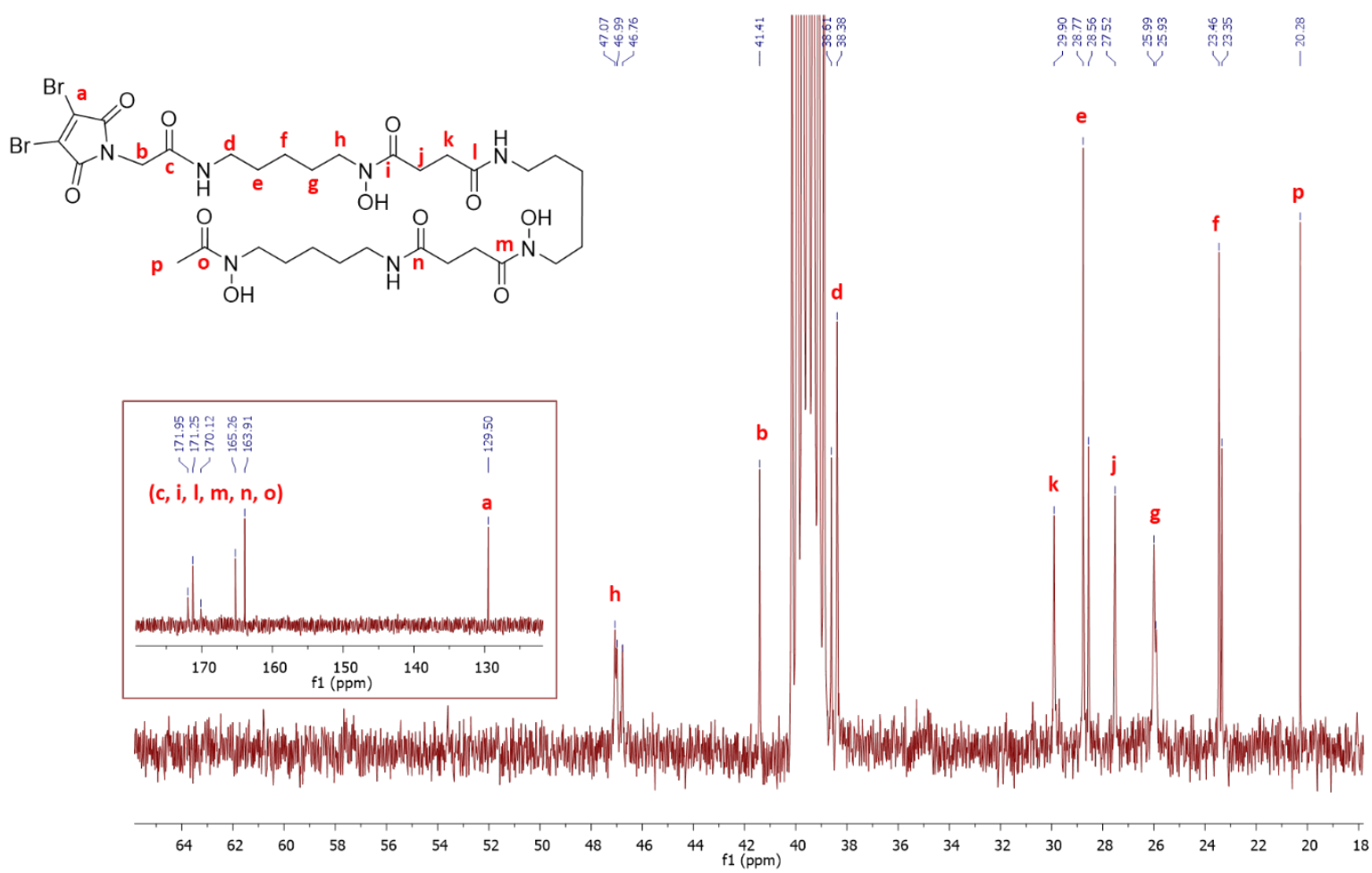

Figure S19. ${ }^{13} \mathrm{C}$ NMR spectrum for dfo-dbm (6) (DMSO- $\mathrm{d}_{6}, 100 \mathrm{MHz}$ ). The similar chemical environment of the atoms along the DFO pentyl and ethyl chains resulted in often coincident, or nearly coincident resonances at $100 \mathrm{MHz}$. 
(a) $\frac{}{133256 \text { \#215-234 RT: } 0.73-0.79 \text { AV: } 20 \text { NL: } 3.49 \mathrm{ET}}$

T: FTMS + p ESI Full ms [150.00-1000.00]

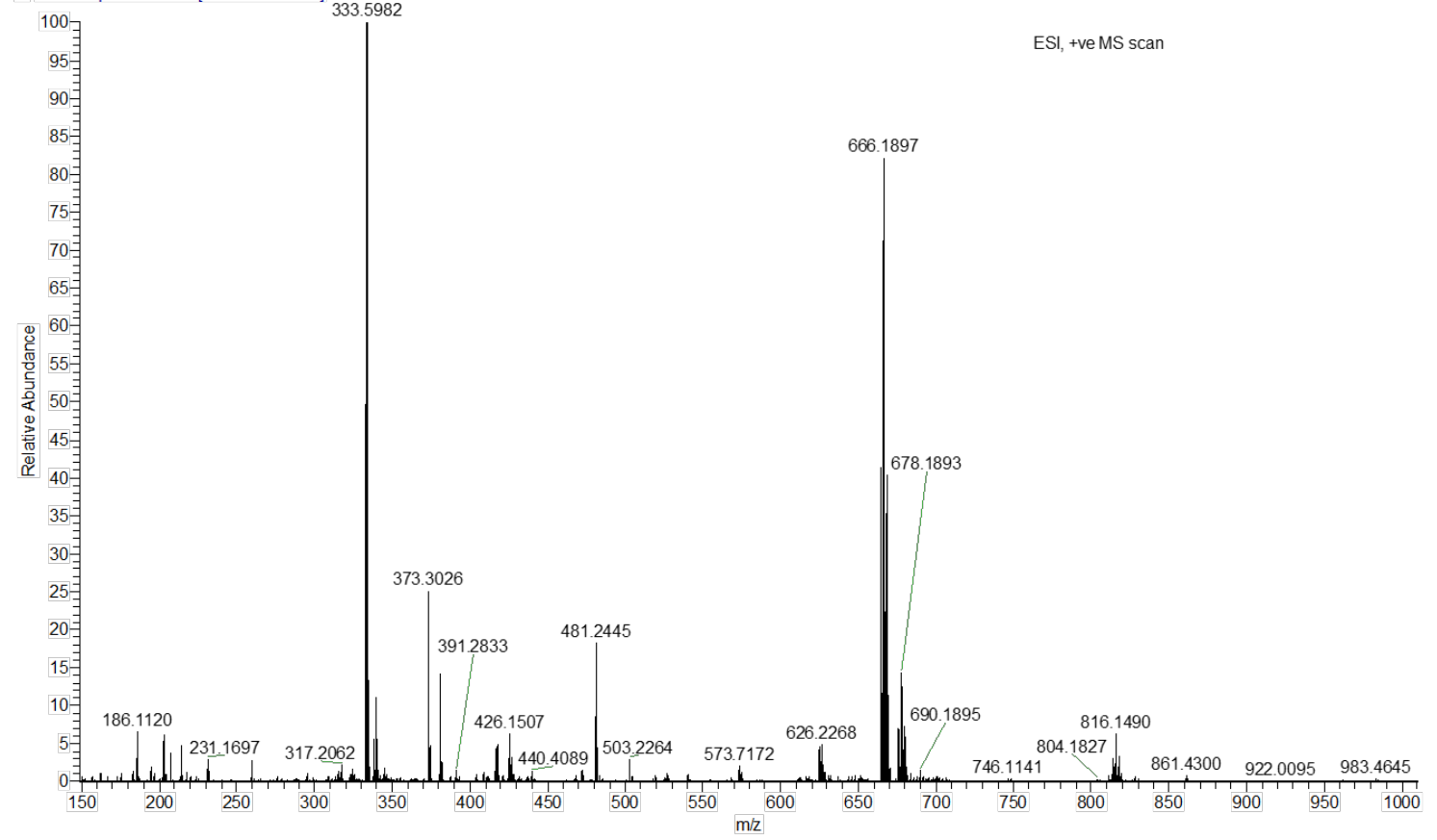

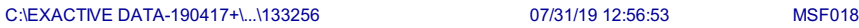

(b)

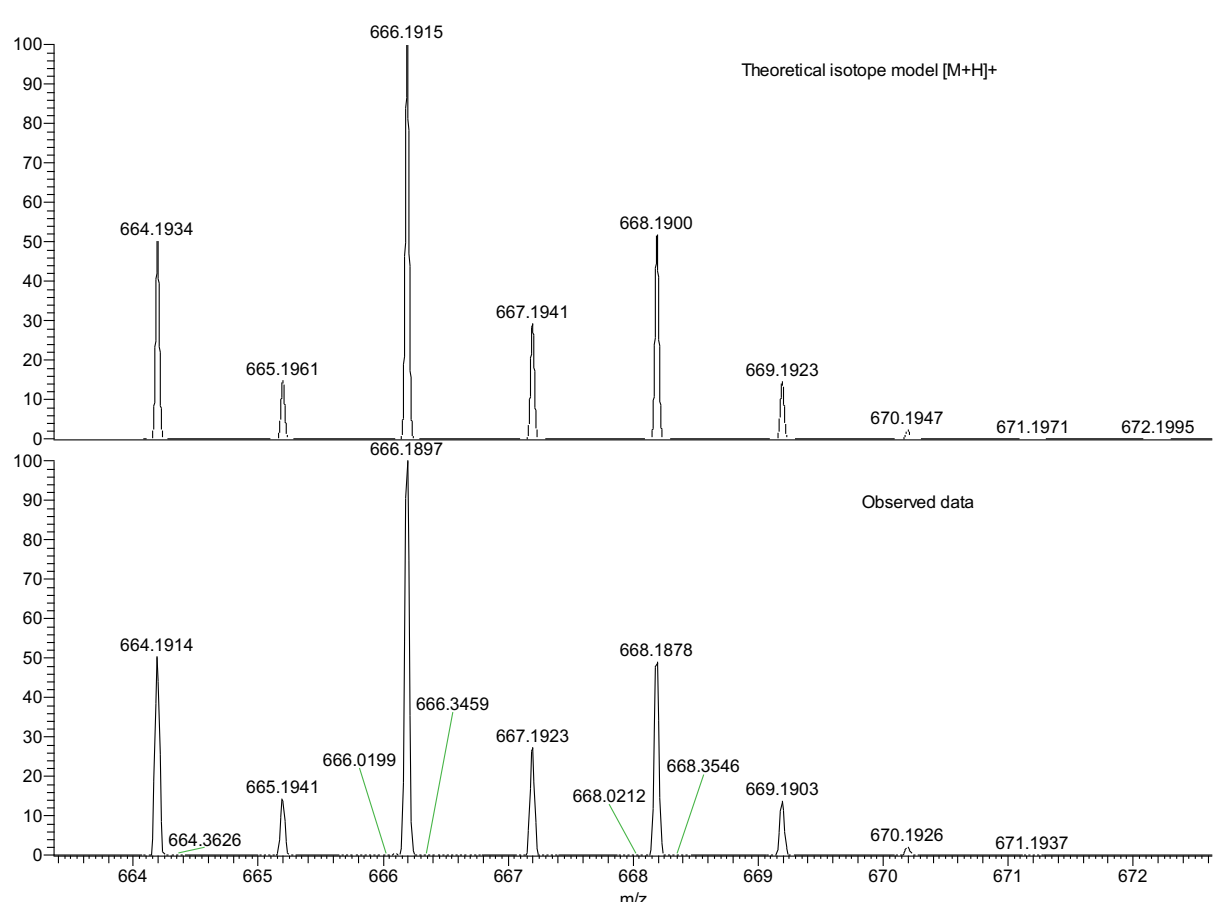

8.:

$\mathrm{C}_{24} \mathrm{H}_{44} \mathrm{Br}_{2} \mathrm{~N}_{9} \mathrm{O}_{3}+\mathrm{H}$

R:20000 Res.Pwr.@FWHM

NL:

133256\#215-234 RT

0.73-0.79 AV: 20 T: FTMS +

[150.00-1000.00]

Figure S20. High-resolution ESI-mass spectrum for sar-dbm: (a) full mass spectrum; (b) expanded view of the [MH] ${ }^{+}$signal showing (top) calculated isotope pattern, and (bottom) observed data. 
134617 \#5-20 RT: 0.07-0.24 AV: 8 NL: $1.39 \mathrm{E} 6$

T: FTMS $\{1,1\}+p$ ESIFull ms [100.00-1000.00]

(a)

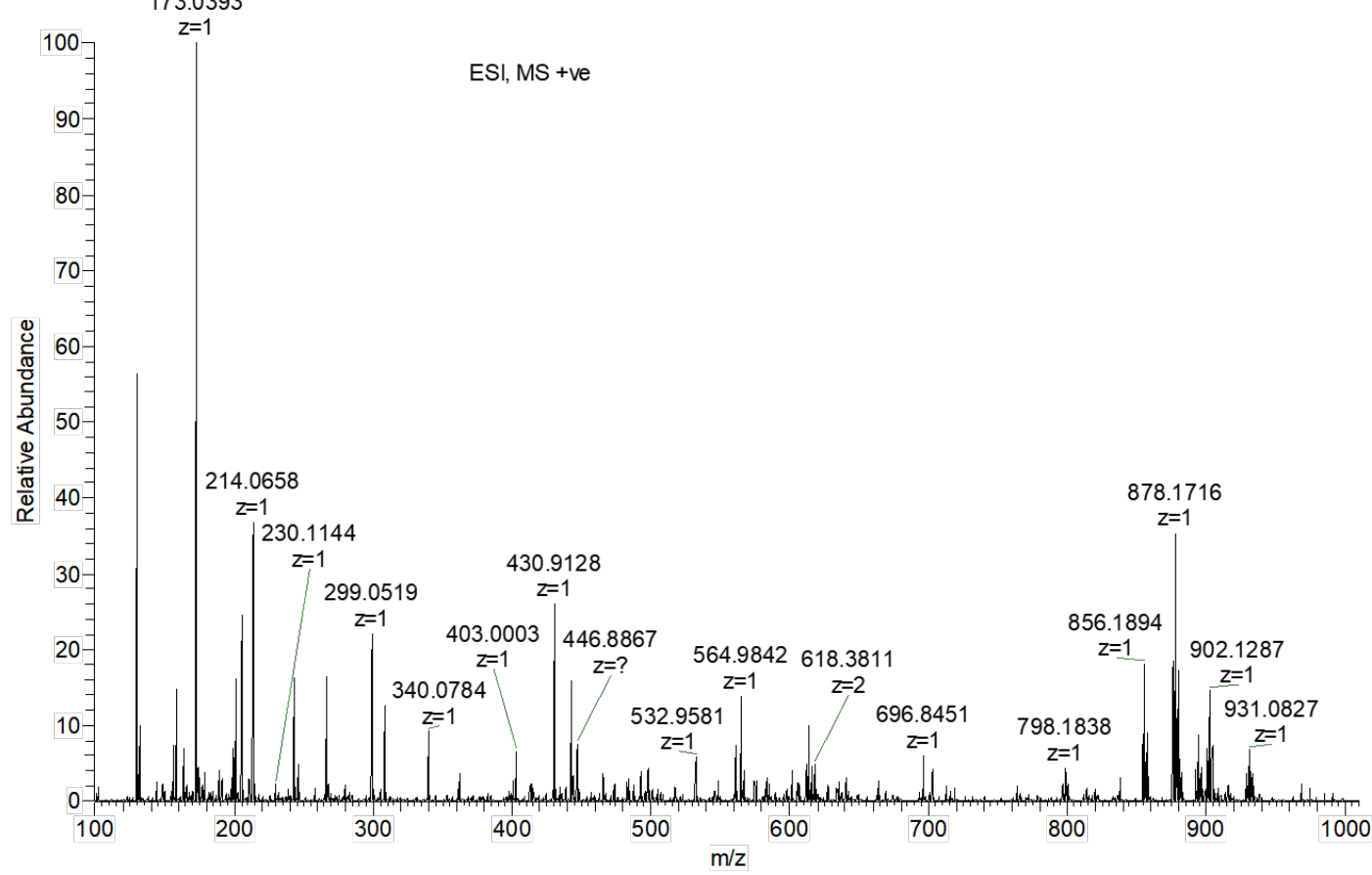

C.IEXACTVE DATA-190417+1, 1134617

10/16/20 15:13:21

MSF023

(b)

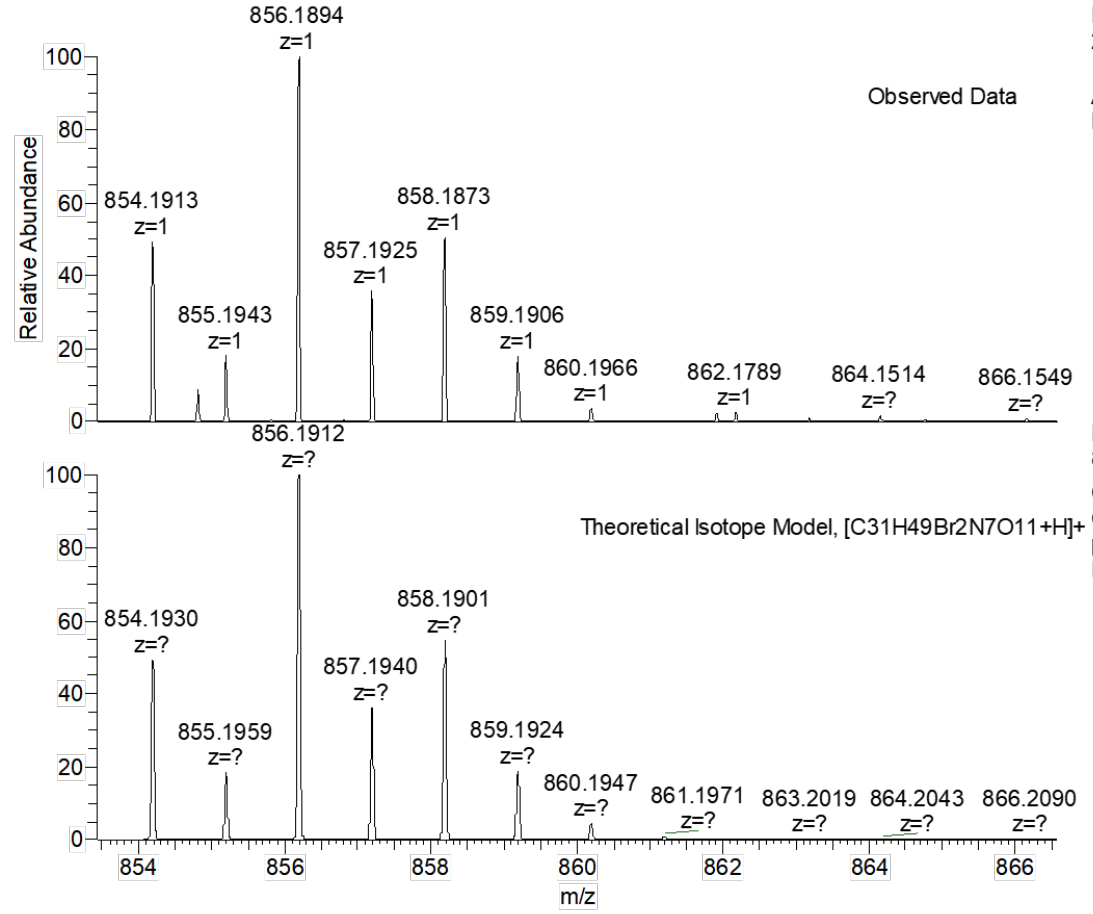

$\mathrm{NL}$

$2.52 \mathrm{E} 5$

34617\#5-20 RT: 0.07-0.24

AV: 8 T: FTMS $\{1,1\}+p$ ES

Full $\mathrm{ms}[100.00-1000.00]$

$\mathrm{NL}:$ .26E3

$\mathrm{C}_{31} \mathrm{H}_{49} \mathrm{Br}_{2} \mathrm{~N}_{7} \mathrm{O}_{11}+\mathrm{H}$ $\mathrm{C}_{31} \mathrm{H}_{50} \mathrm{Br}_{2} \mathrm{~N}_{7} \mathrm{O}_{11}$

R: 20000 Res.Pwr. @FWHM

showing (top) observed data and (bottom) calculated isotope pattern. 


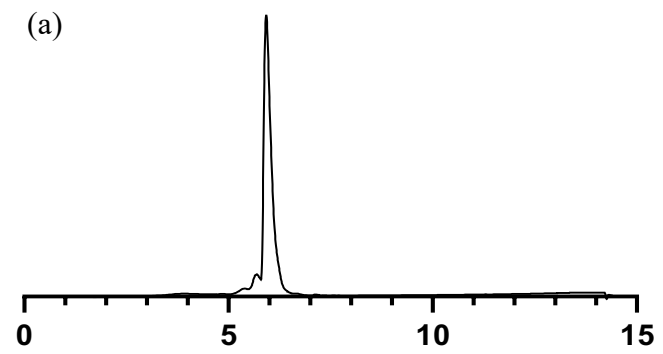

Retention time ( $\mathrm{min})$

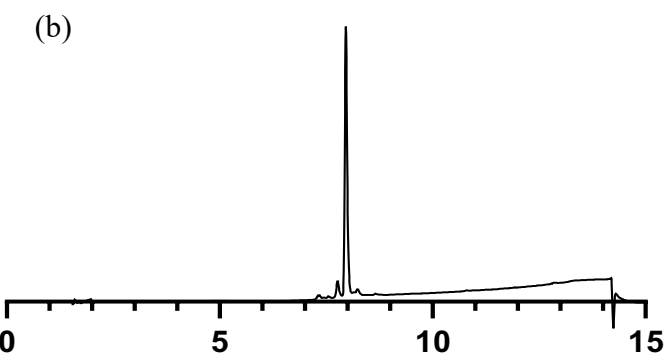

Retention time ( $\mathrm{min})$

Figure S22. Analytical C18 reverse-phase HPLC chromatograms with UV detection at $\lambda 254$ of (a) sar-dbm with a retention time of $5.92 \mathrm{~min}$ and (b) dfo-dbm with a retention time of $7.95 \mathrm{~min}$. Agilent ZORBAX Eclipse XDB-C18, 80Å, $4.6 \times 150 \mathrm{~mm}, 5$

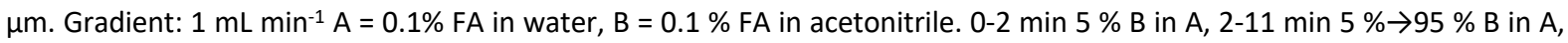
$12-12.10 \min 95 \% \rightarrow 5 \%$ B in $A, 12.10-15 \min 5 \% B$ in $A$. 
(a)

Intensity WWD: Signal A, $220 \mathrm{~nm}$

(b)

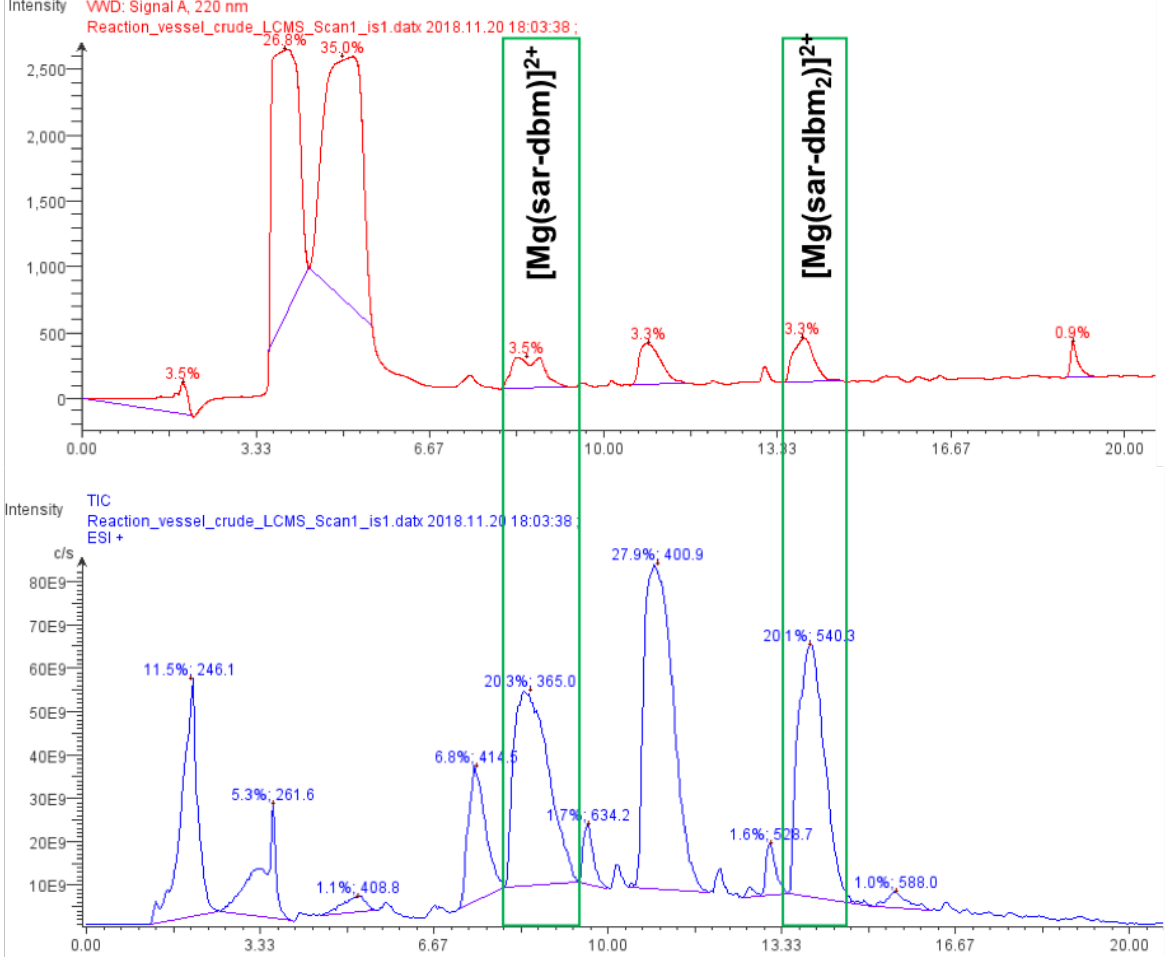

(c)

$\begin{array}{ll}\text { Intensity } & \text { Spectrum RT 8.15 - 9.32 \{34 scans\} } \\ & \text { Reaction_vessel_crude_LCMS_Scan1_is1.datx 2018.11.20 18:03:38 }\end{array}$

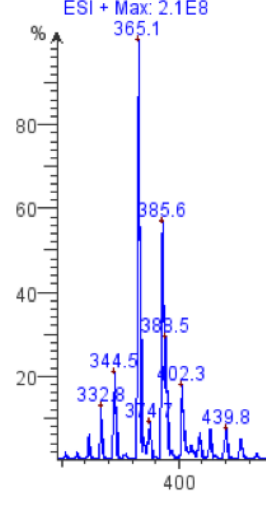

$[\mathrm{Mg}(\mathrm{sar}-\mathrm{dbm})]^{2+}$

$\left[\mathrm{C}_{24} \mathrm{H}_{43} \mathrm{Br}_{2} \mathrm{~N}_{9} \mathrm{O}_{3}+\mathrm{Mg}\right]^{2+}$

Calculated $\mathrm{m} / \mathrm{z} 344.6$

Observed $\mathrm{m} / \mathrm{z} 344.5$

$\left[\mathrm{C}_{24} \mathrm{H}_{43} \mathrm{Br}_{2} \mathrm{~N}_{9} \mathrm{O}_{3}+\mathrm{Mg}+\mathrm{CH}_{3} \mathrm{CN}\right]^{2+}$

Calculated $\mathrm{m} / \mathrm{z} 365.1$

Observed $\mathrm{m} / \mathrm{z} 365.1$

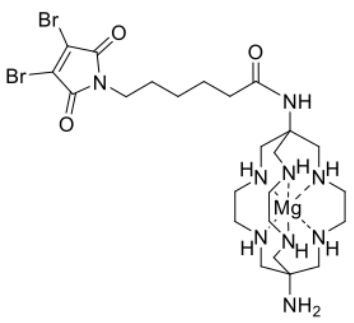

(d)

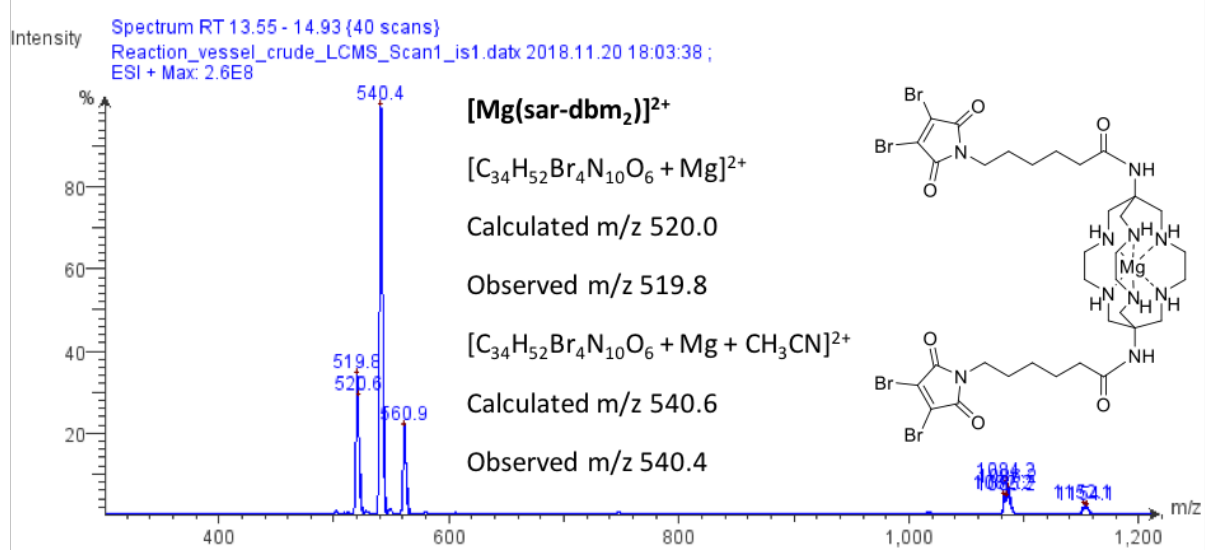

Figure S23. The compound $\left[\mathrm{Mg}\left(\text { sar- } \mathrm{dbm}_{2}\right)\right]^{2+}$ was also observed in reactions containing $\left[\mathrm{Mg}\left(\left(\mathrm{NH}_{2}\right)_{2} \mathrm{sar}\right)\right]^{2+}$ and 3,4-dibromomaleimide- $N$-hexanoic acid. In this compound, both apical primary amines of $\left(\mathrm{NH}_{2}\right)_{2}$ sar ligand react with two equivalents of 3,4-dibromo-maleimide- $N$-hexanoic acid to yield a sarcophagine chelator containing two dibromomaleimide groups. LC-MS analysis of crude reaction mixtures showed the presence of both sar- $\mathrm{dbm}$ and sar-dbm $\mathrm{db}_{2}$ (a) UV chromatogram $(\lambda=220 \mathrm{~nm})$; (b) total ion current chromatogram (positive mode); (c) Mass spectrum of $\left[\mathrm{Mg}(\text { sar- } \mathrm{dbm} \text { ) }]^{2+}\right.$ (retention time $=8.15 \mathrm{~min}$ ); (d) Mass spectrum of $\left[\mathrm{Mg}\left(\mathrm{sar}-\mathrm{dbm}_{2}\right)\right]^{2+}$ (retention time $\left.=13.55 \mathrm{~min}\right)$. 
(a)

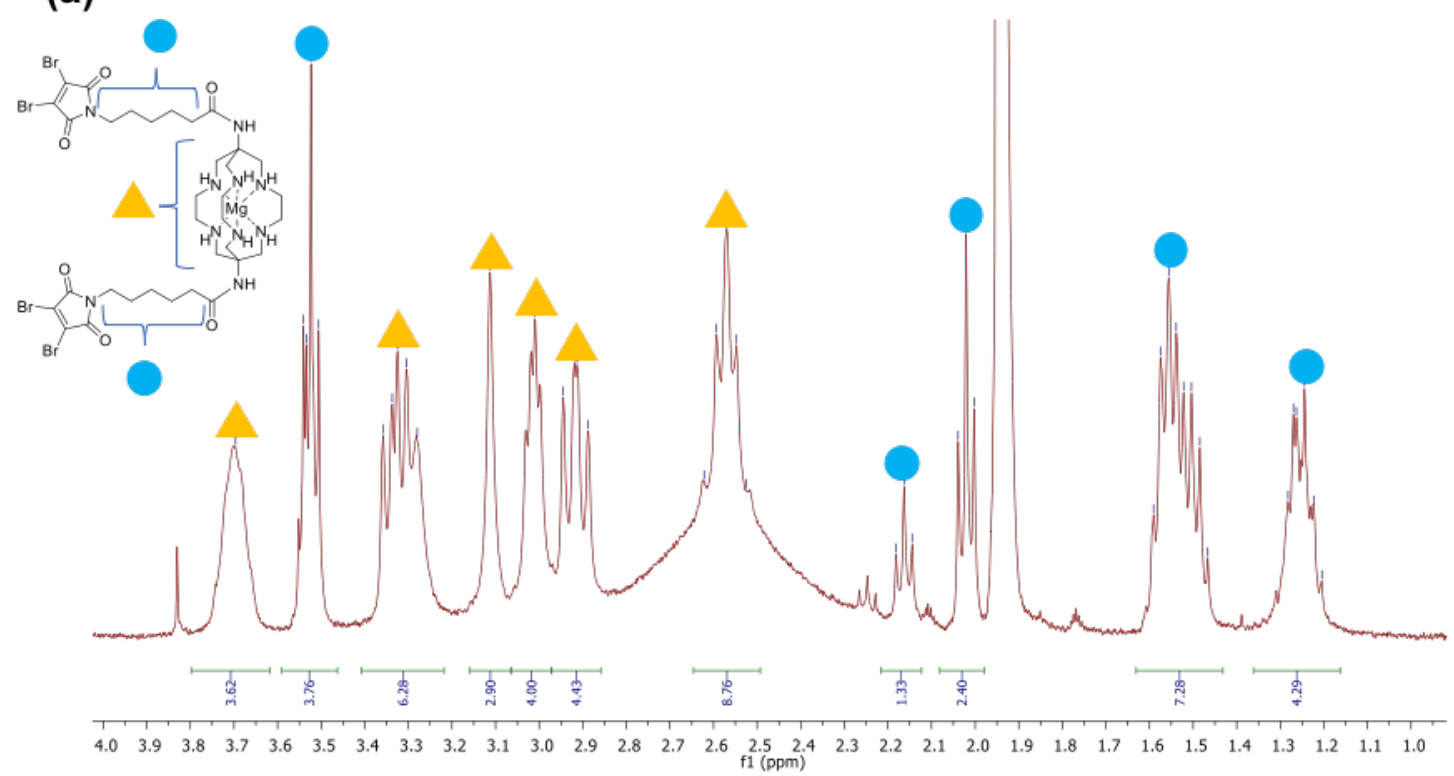

(b)

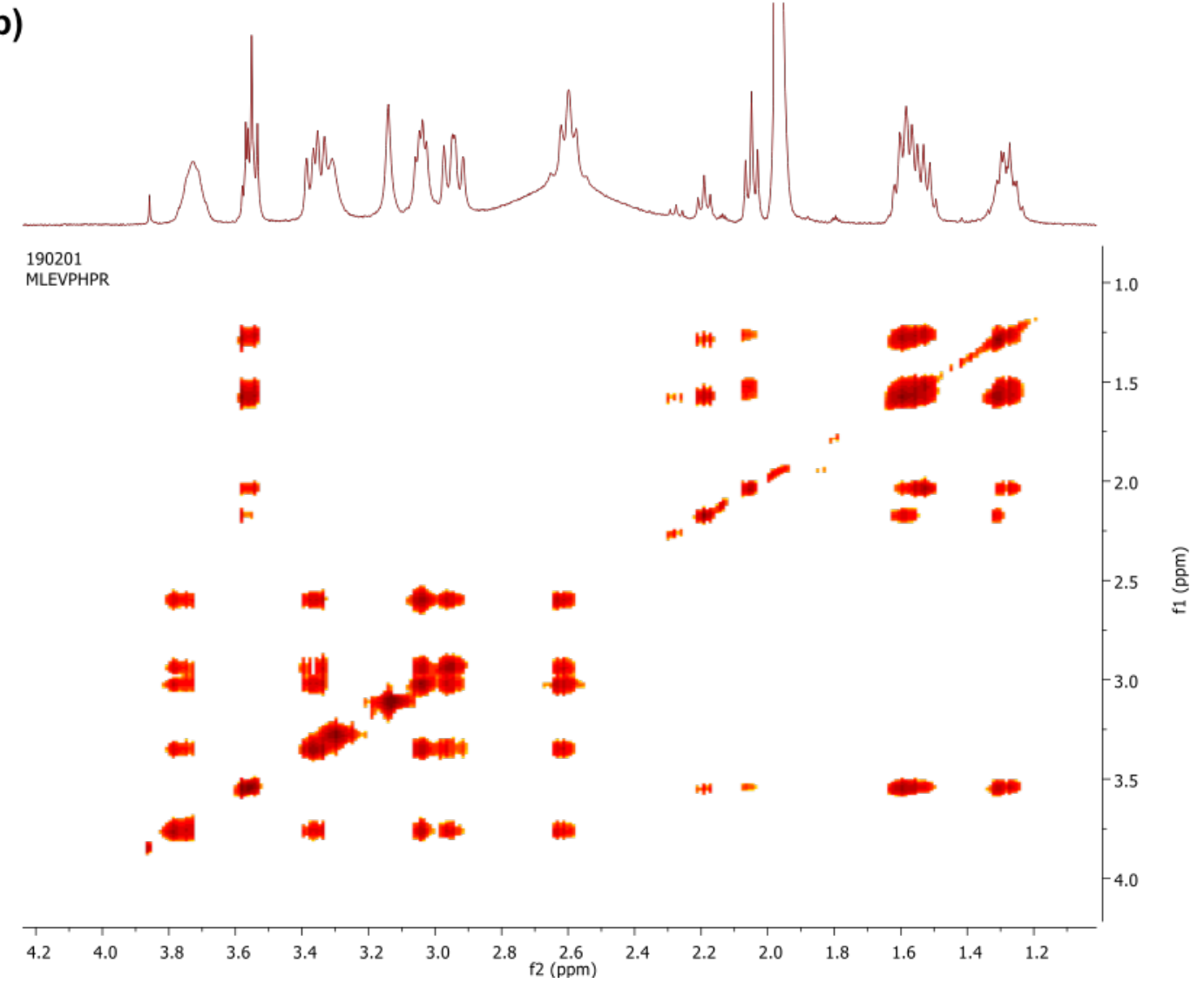

Figure S24. (a) ${ }^{1} \mathrm{H}$ NMR spectrum obtained for isolated $\left[\mathrm{Mg}\left(\text { sar- } \mathrm{dbm}_{2}\right)\right]^{2+}\left(\mathrm{CD}_{3} \mathrm{CN}, 400 \mathrm{MHz}\right)$. (b) ${ }^{1} \mathrm{H}$ TOCSY NMR spectrum obtained for $\left[\mathrm{Mg}\left(\mathrm{sar}-\mathrm{dbm}_{2}\right)\right]^{2+}\left(\mathrm{CD}_{3} \mathrm{CN}, 400 \mathrm{MHz}\right)$. N.B.: This material was isolated from a crude reaction in which $\mathrm{Mg}^{2+}$ was not removed from sar derivatives, prior to HPLC purification. 
(a)

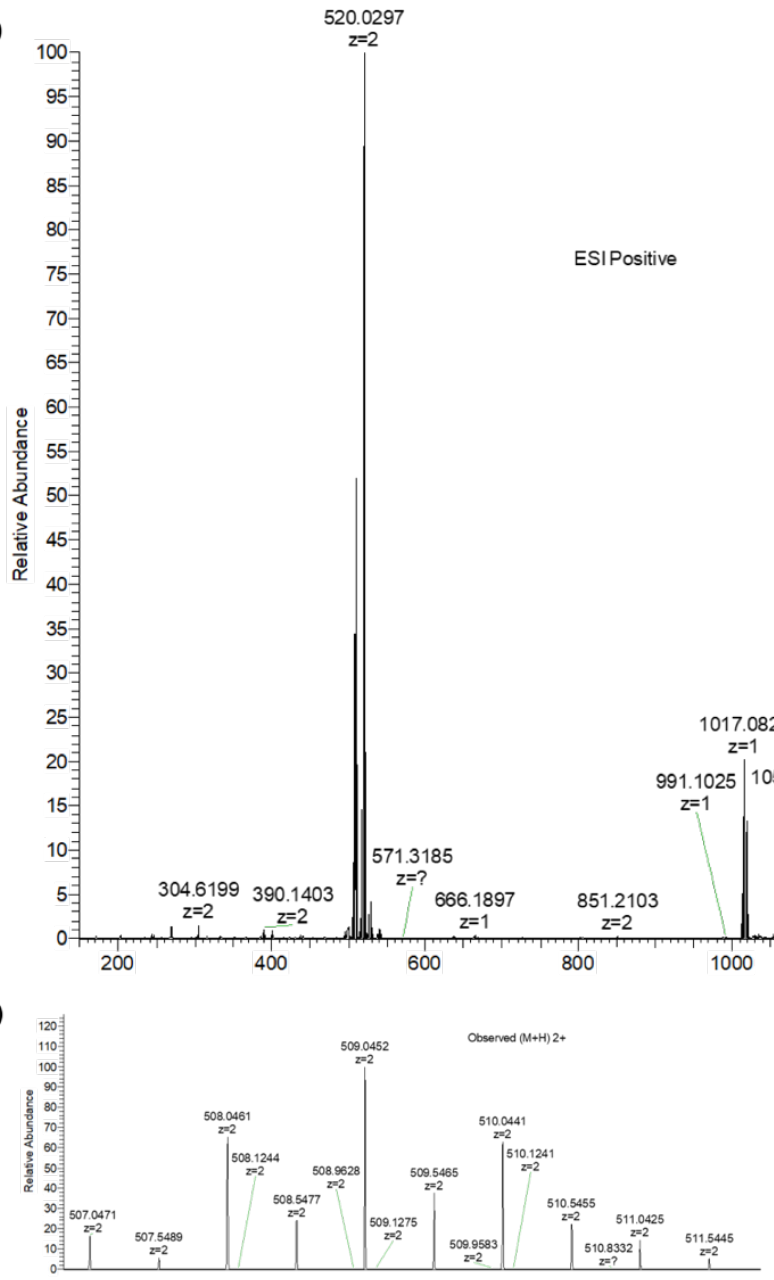

(c)

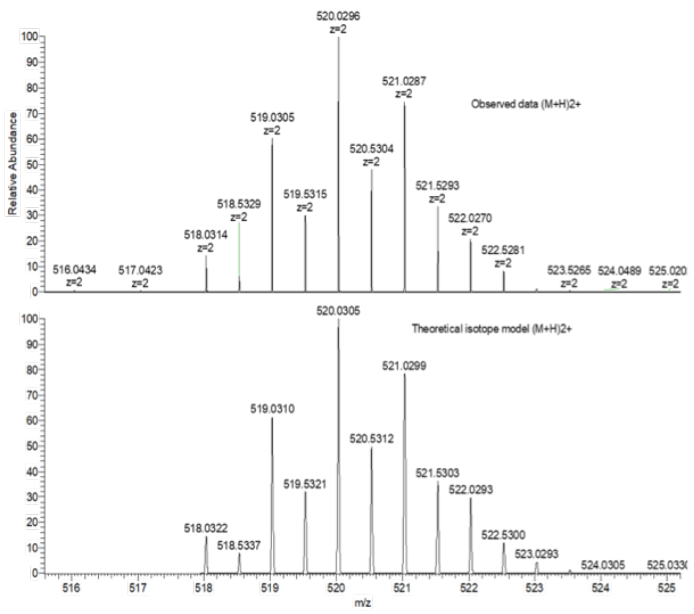

1.082

(1059.0599

59.0599

1153.0444

$\begin{array}{llllll}1200 & 1400 & 1600 & 1800 & 2000\end{array}$

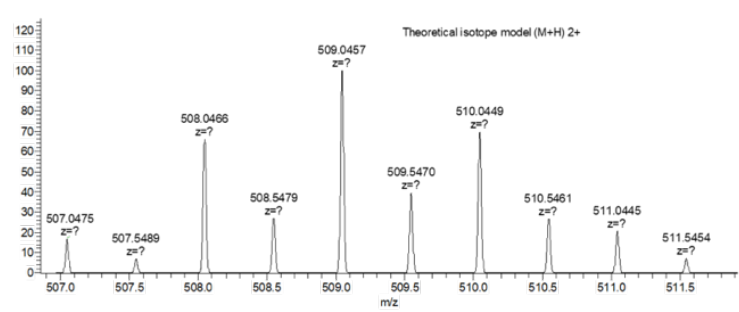

(b)
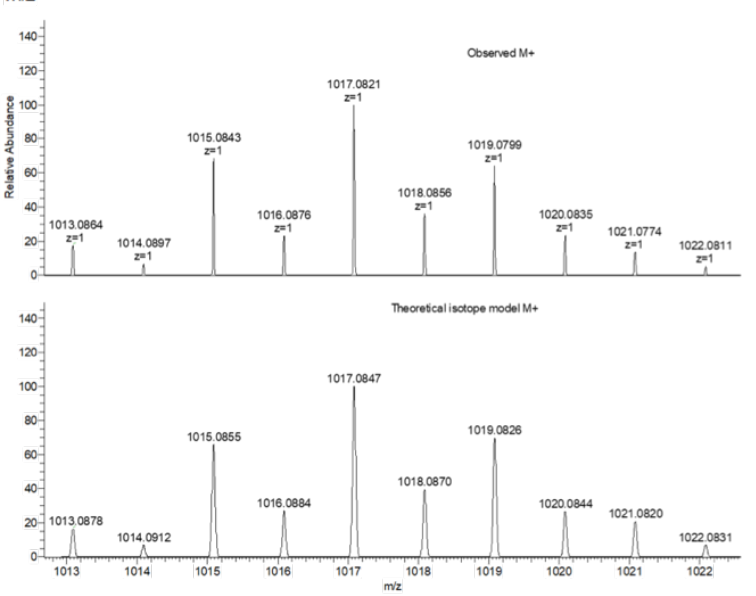

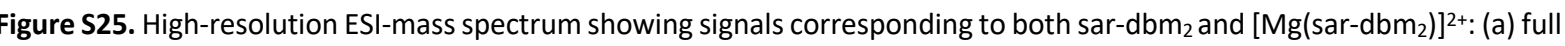
mass spectrum; (b) expanded view of signals corresponding to sar-dbm 2 showing (top) observed data and (bottom) theoretical isotope pattern; (c) expanded view of signals corresponding to $\left[\mathrm{Mg}\left(\mathrm{sar}-\mathrm{dbm}_{2}\right)\right]^{2+}$ showing (top) observed data and (bottom) calculated isotope pattern. 


\section{References}

1. Geue, R. J., Sargeson, A. M., Hambley, T. W., Snow, M. R., Harrowfield, J. M., (1984) Metal lon Encapsulation: Cobalt Cages Derived from Polyamines, Formaldehyde, and Nitromethane. J. Am. Chem. Soc. $106,5478-5488$.

2. Clark, I. J., Creaser, I. I., Geue, R. J., Hagen, K. S., Lawrance, G. A., Lay, P. A., Sargeson, A. M., Wilne, F. R., (1994) The Synthesis and Structure of Encapsulating Ligands: Properties of Bicyclic Hexamines. Aust. J. Chem. 47, 143-179.

3. Paterson, B. M., Buncic, G., Mclnnes, L. E., Roselt, P., Cullinane, C., Binns, D. S., Jeffery, C. M., Price, R. I., Hicks, R. J., Donnelly, P. S. (2015) Bifunctional ${ }^{64} \mathrm{Cu}$-Labelled Macrobicyclic Cage Amine Isothiocyanates for Immuno-Positron Emission Tomography. Dalton Trans., 44, 4901-4909.

4. Morais, M., Nunes, J. P. M., Karu, K., Forte, N., Benni, I., Smith, M. E. B., Caddick, S., Chudasama, V., Baker, J. R. (2017) Optimisation of the Dibromomaleimide (DBM) Platform for Native Antibody Conjugation by Accelerated Post-Conjugation Hydrolysis. Org. Biomol. Chem. 15, 2947-2952.

5. Morais, M.; Forte, N.; Chudasama, V.; Baker, J. R. Application of Next-Generation Maleimides (NGMs) to Site-Selective Antibody Conjugation, in Methods in Molecular Biology; Massa, S., Devoogdt, N., Eds.; Humana: New York, 2019; Vol. 2033, pp 15-24.

6. Cooper, M. S., Ma, M. T., Sunassee, K., Shaw, K. P., Williams, J. D., Paul, R. L., Donnelly, P. S., and Blower, P. J. (2012) Comparison of ${ }^{64} \mathrm{Cu}$-Complexing Bifunctional Chelators for Radioimmunoconjugation: Labeling Efficiency, Specific Activity, and in Vitro / in Vivo Stability. Bioconjugate Chem. 23, 1029-1039.

7. Man, F. Khan, A. A., Carrascal-Miniño, A., Blower, P. J., de Rosales, R. T. M. (2020) A Kit Formulation for the Preparation of $\left.{ }^{89} \mathrm{Zr}\right] \mathrm{Zr}$ (oxinate) ${ }_{4}$ for PET Cell Tracking: White Blood Cell Labelling and Comparison with [111 In] In(oxinate) 3 . Nucl. Med. Biol. 90-91, 31-40. 